\title{
Antimicrobial and micronutrient interventions for the management of infants under 6 months of age identified with severe malnutrition: a literature review
}

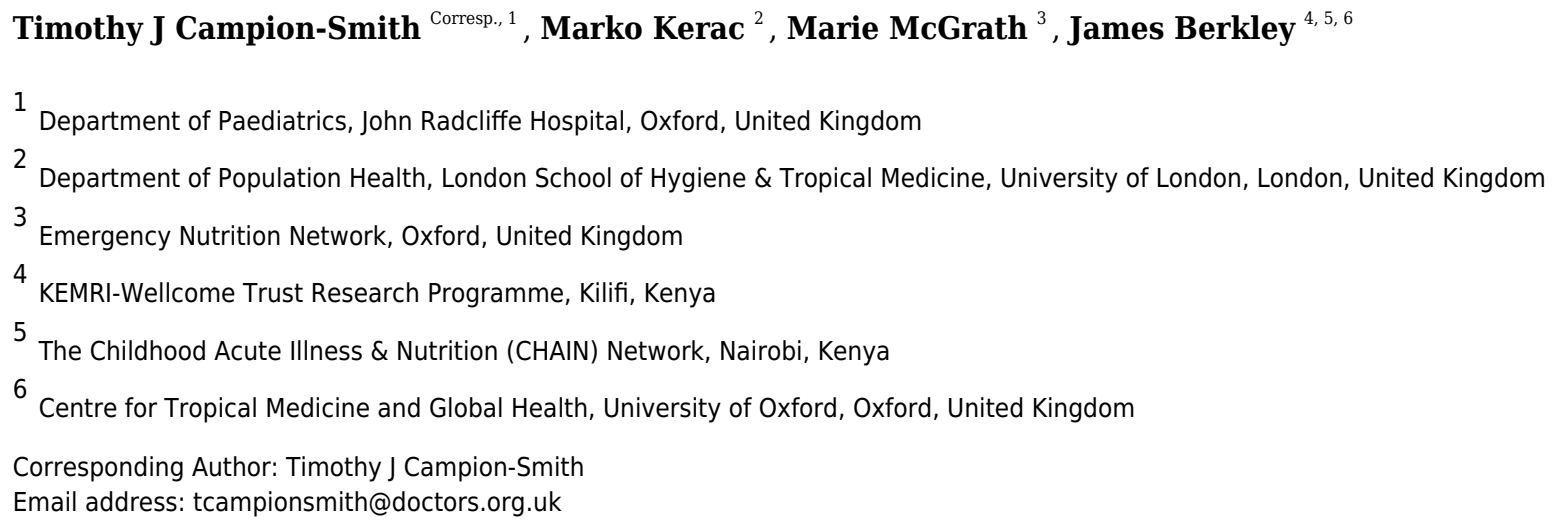

Background. Infants under 6 months (U6M) contribute a significant proportion of the burden and mortality of severe malnutrition globally. Evidence of underlying aetiology in this population is sparse, but it is known that the group includes ex-preterm and low birthweight (LBW) infants. They represent a unique population given their dependence on breastmilk or a safe, secure alternative. Nutrition agencies and health providers struggle to make programming decisions on which interventions should be provided to this group based upon the 2013 WHO Guidelines for the 'Management of Severe Acute Malnutrition in Infants and Young Children' since there are no published interventional trial data focussed on this population. Interim guidance for this group might be informed by evidence of safety and efficacy in adjacent population groups. Methodology. A narrative literature review was performed of systematic reviews, meta-analyses and randomised controlled trials of antimicrobial and micronutrient interventions (antibiotics, deworming, vitamin A, vitamin $D$, iron, zinc, folic acid and oral rehydration solution (ORS) for malnutrition) across the population groups of low birthweight/preterm infants, infants under 6 months, infants and children over 6 months with acute malnutrition or through supplementation to breastfeeding mothers. Outcomes of interest were safety and efficacy, in terms of mortality and morbidity. Results. Ninety-four articles were identified for inclusion within this review. None of these studied interventions exclusively in severely malnourished infants U6M. $64 \%$ reported on the safety of studied interventions. Significant heterogeneity was identified in definitions of study populations, interventions provided, and outcomes studied. The evidence for efficacy and safety across population groups is reviewed and 
presented for the interventions listed. Conclusions. The direct evidence base for medical interventions for severely malnourished infants U6M is sparse. Our review identifies a specific need for accurate micronutrient profiling and interventional studies of micronutrients and oral fluid management of diarrhoea amongst infants U6M meeting anthropometric criteria for severe malnutrition. Indirect evidence presented in this review may help shape interim policy and programming decisions as well as the future research agenda for the management of infants U6M identified as malnourished. 


\section{Antimicrobial and micronutrient interventions for the} 2 management of infants under 6 months of age 3 identified with severe malnutrition: a literature review

4

5

6

7

8
Timothy J Campion-Smith ${ }^{1}$, Marko Kerac ${ }^{2}$, Marie McGrath ${ }^{3}$, James A Berkley ${ }^{4,5,6}$

${ }^{1}$ Department of Paediatrics, John Radcliffe Hospital, Oxford, United Kingdom

2 Department of Population Health, London School of Hygiene \& Tropical Medicine, University of London, London, United Kingdom

${ }^{3}$ Emergency Nutrition Network, Oxford, United Kingdom

${ }^{4}$ KEMRI-Wellcome Trust Research Programme, Kilifi, Kenya

${ }^{5}$ The Childhood Acute Illness \& Nutrition (CHAIN) Network, Nairobi, Kenya

${ }^{6}$ Centre for Tropical Medicine and Global Health, University of Oxford, Oxford, United

Kingdom

Corresponding Author:

Timothy J Campion-Smith

Department of Paediatrics, John Radcliffe Hospital, Headley Way, Oxford, OX3 9DU, United Kingdom

Email address: tcampionsmith@doctors.org.uk 


\section{Abstract}

Background. Infants under 6 months (U6M) contribute a significant proportion of the burden and mortality of severe malnutrition globally. Evidence of underlying aetiology in this population is sparse, but it is known that the group includes ex-preterm and low birthweight (LBW) infants. They represent a unique population given their dependence on breastmilk or a safe, secure alternative. Nutrition agencies and health providers struggle to make programming decisions on which interventions should be provided to this group based upon the 2013 WHO Guidelines for the 'Management of Severe Acute Malnutrition in Infants and Young Children' since there are no published interventional trial data focussed on this population. Interim guidance for this group might be informed by evidence of safety and efficacy in adjacent

Methodology. A narrative literature review was performed of systematic reviews, meta-analyses and randomised controlled trials of antimicrobial and micronutrient interventions (antibiotics, deworming, vitamin A, vitamin D, iron, zinc, folic acid and oral rehydration solution (ORS) for malnutrition) across the population groups of low birthweight/preterm infants, infants under 6 months, infants and children over 6 months with acute malnutrition or through supplementation to breastfeeding mothers. Outcomes of interest were safety and efficacy, in terms of mortality and morbidity.

Results. Ninety-four articles were identified for inclusion within this review. None of these studied interventions exclusively in severely malnourished infants U6M. 64\% reported on the safety of studied interventions. Significant heterogeneity was identified in definitions of study populations, interventions provided, and outcomes studied. The evidence for efficacy and safety across population groups is reviewed and presented for the interventions listed.

50

Conclusions. The direct evidence base for medical interventions for severely malnourished infants U6M is sparse. Our review identifies a specific need for accurate micronutrient profiling and interventional studies of micronutrients and oral fluid management of diarrhoea amongst infants U6M meeting anthropometric criteria for severe malnutrition. Indirect evidence presented in this review may help shape interim policy and programming decisions as well as the future research agenda for the management of infants U6M identified as malnourished. 


\section{Introduction}

59 Malnutrition remains a major problem globally with an estimated 22.4 million children under 5

60

61

62

63

64

65

66

67

68

69

70

71

72

73

74

75 76

77

78

79

80

81

82

83

84

85

86

87

88

89

90

91

92

93

94

95

96

years old affected by severe wasting ${ }^{1}$, and with all forms of undernutrition being a causal factor in $45 \%$ of childhood mortality ${ }^{2}$. Recently, there has been increasing awareness that infants under 6 months (U6M) make up a sizable proportion of these children, with 3.8 million infants U6M estimated as severely wasted (weight-for-length $<3$ standard deviations below median, as per current WHO definition) and 4.7 million moderately wasted (weight-for-length between 3 and 2 standard deviations below median) ${ }^{3}$. Mortality rates are higher in this group compared to their counterparts aged over 6 months ${ }^{4}$. However, the total number of infants U6M with any anthropometric indicator of malnutrition (including moderate wasting, stunting, low weight-forage or low mid upper arm circumference (MUAC)) and who are therefore at increased risk of morbidity and mortality, is significantly greater. This population group typically includes some infants who were born preterm or with low birthweight (LBW) as well as those with primary or secondary (i.e. resulting from illness) malnutrition ${ }^{5,6}$. This is a unique population who are nutritionally dependent on breastmilk (or a safe, secure alternative), whilst at increased risk of serious common infections compared to older children as their immunity develops. Hence, they do not fit neatly into either neonatal nutritional guidelines or guidelines for therapeutic feeding programmes among children over 6 months of age.

The 2013 update of the World Health Organization (WHO) guidelines on Severe Acute Malnutrition (SAM) was the first to include specific recommendations for infants U6M, accommodating both inpatient and outpatient care of complicated (i.e. clinically unstable as well as malnourished) and uncomplicated (i.e. clinically still stable despite anthropometric compromise) respectively ${ }^{7}$. These guidelines focus on acute malnutrition as defined by low weight-for-length, however there is increasing recognition that other anthropometric indicators (low weight-for-age, low MUAC, mid upper arm circumference) may better identify high-risk infants ${ }^{8}$. Hence, in this paper, we deliberately use the term 'severe malnutrition' to identify our target group: those small infants U6M who, as per WHO 2013 SAM guidelines, are at high risk of mortality, morbidity and future neurodevelopmental impairment ${ }^{9}$.

Whilst the WHO 2013 guidelines for managing malnutrition among infants U6M make numerous recommendations, the key focus is on feeding support, with the aim of re-establishing effective exclusive breastfeeding. Other important aspects of care are less well described, with suggestions that infants U6M receive "the same general medical care as infants with severe acute malnutrition (SAM) who are 6 months of age or older ${ }^{7}$. Thus, there is ambiguity in how these guidelines should be interpreted and implemented, making programming difficult for nutrition agencies, policymakers and health providers. This review was directly prompted by questions to the Emergency Nutrition Network (ENN) from nutrition agencies and health providers as to which interventions besides breastfeeding support are safe, effective and should

PeerJ reviewing PDF | (2019:09:41387:1:1:NEW 14 Apr 2020) 
97 be prioritised (e.g. antibiotic treatment, deworming, micronutrient supplementation and oral

98 rehydration) in the management of acutely malnourished infants $\mathrm{U}^{6} \mathrm{M}^{10}$.

99

100

101

Recommendations on the management of severe malnutrition in infants U6M are currently

102 hampered by lack of evidence in this age group, acknowledged in the WHO 2013 SAM guideline update $^{7}$. Besides shorter-term risks of death and morbidity, there are important long-term

104 consequences for neurodevelopment and adult non-communicable disease ${ }^{11}$. The determinants of severe malnutrition in infants U6M are only just beginning to be studied ${ }^{12}$. It is not yet clear what proportion of infants are presenting with acute wasting as opposed to following a trajectory from LBW, whether premature or small for gestational age (SGA), and whether this has implications for assessment and treatment.

108

109

In the absence of specific evidence, interim guidance might be informed by the evidence and guidelines developed for infants close in age (LBW) or nutritional status (malnourished children age 6 months or more). By way of background, the current WHO recommendations for micronutrient supplementation in very LBW (VLBW)/LBW infants and for children with SAM are summarised in Table 1.

114

Table 1: Summary of current recommendations for antimicrobial and micronutrient supplementation amongst $\mathrm{LB} W / V L B W$ infants and children with $S A M(W H O)^{7,13}$

This literature review aims to summarise evidence for antimicrobial and micronutrient treatments that might inform policies for management of infants U6M identified as severely malnourished. Objectives towards this are: to identify evidence from adjacent paediatric populations (LBW infants and infants and children aged $>6$ months with severe malnutrition) on micronutrient supplementation and antimicrobial interventions; to summarise what this evidence shows in terms of safety and efficacy; and to identify critical areas needing future research.

Key abbreviations and definitions used throughout the article are presented in Figure 1. Whilst our focus is on infants U6M with severe malnutrition, where an article is cited within a malnourished population, that article's terminology with regard to malnutrition is presented in inverted commas. For ease of interpretation, we present data in the following age categories, LBW/preterm, infants U6M, and children over 6 months (up to 18 years but with the majority of included articles focusing on 6-59months). This is to reflect the structure the current WHO SAM guidelines as U6M and over 6 months, recognising that a significant proportion of the at-risk U6M population may have been born LBW/preterm or both.

133

\section{Figure 1: Abbreviations and definitions}

135 
137

138

139

140

141

142

143

144

145

146

147

148

149

150

151

152

153

154

155

156

157

158

159

160

161

162

163

164

165

166

167

168

169

170

171

172

173

174

\section{Survey methodology}

In this scoping review, PubMed and Google Scholar databases were searched on $1^{\text {st }}$ October 2018 to identify systematic reviews (SRs), meta-analyses (MAs) and randomised-controlled trials (RCTs) where the full-text was available in English. Populations included in the search criteria were infants U6M (with or without severe malnutrition), infants and children over the age of 6 months (with or without severe malnutrition), pre-term/LBW/VLBW infants and breastfeeding mothers. Any definition of severe malnutrition was included. The interventions included were those mentioned in the current WHO guidelines for the management of SAM in those over the age of 6 months $^{7}$ and for the management of LBW/VLBW infants ${ }^{13}$ : antibiotics, deworming, vitamin A, vitamin D, iron, zinc, folic acid and oral rehydration solution (ORS) for malnutrition (ReSoMal), as well as maternal micronutrient and macronutrient supplementation in the post-natal period up to 6 months of age (not from WHO guideline). Outcomes of interest were mortality, morbidity, anthropometric changes, neurodevelopment and adverse effects on the infant or child.

The following were considered outside the scope of this review: breast milk fortifiers; pre-natal nutritional supplementation; breastfeeding support interventions; and the duration, mechanism of delivery and cost of interventions.

Identified articles were screened for suitability and reviewed by the first author. Where the results of an RCT were included and presented in a subsequent MA, the article was not included unless it contained a subgroup population of interest (e.g. malnourished infants and children) that was not presented or the primary population of interest in the MA. Similarly, where a study looked primarily at multiple micronutrient interventions, this was included if the effects of including or excluding a single micronutrient. When LBW is mentioned, it refers to studies that defined a population as either SGA, pre-term or LBW $(<2.5 \mathrm{~kg})$. When VLBW is mentioned, it refers specifically to a study of $<1.5 \mathrm{~kg}$ birth weight.

A formal GRADE assessment for quality of evidence of all included articles was beyond the scope of this review but where a GRADE classification of quality (Very

Low/Low/Moderate/High) has been made in a recent SR or MA, this is presented.

\section{Results}


175 We identified a total of 94 articles for inclusion and review. None of these focused exclusively 176 on severely malnourished infants U6M. Four articles (4\%) examined infants U6M alongside 177 other malnourished children over 6 months; 15 (16\%) RCTs included malnourished children 178 (both U6M and up to age 14 years). No subgroup analysis by age was presented in any of these 179 articles. Figure 2 displays the distribution of evidence by population of interest and by study 180 type.

181

Figure 2: Distribution of included articles presented by population studied and study design

185

186

187

188

189

190

191

192

193

194

195

196

197

198

199

200

201

202

203

204

205

206

207

208

209

210

211

212

213

214 Efficacy
Of included articles, 60 (64\%) documented the presence or absence of adverse effects or addressed safety. Table 2 presents proportion of articles reporting on safety, by intervention.

Table 2: Distribution of studies reporting on adverse effects by antimicrobial or micronutrient intervention

Our search identified marked heterogeneity in: age range of the population studied; anthropometric definitions of malnutrition; dosage and duration of intervention; and outcomes studied. This makes summarising overall direction and size of effect challenging. Key findings by intervention are shown in Table 3 .

Table 3: Summary of results by antimicrobial and micronutrient intervention

\section{Antibiotics}

Current WHO guidance for antibiotic use in management of 'SAM' in infants U6M is to treat inpatient admissions (i.e. those with 'complicated' disease) with intravenous (IV) antibiotics and outpatients (i.e. those with 'uncomplicated' disease) with oral antibiotics, such as amoxicillin. Our search identified eight key articles for inclusion in this review (five in malnourished children over 6 months (two SRs, one MA and three RCTs), one in LBW infants and one published RCT that included malnourished infants U6M). Summarising a literature-base that includes multiple drug classes with different pharmacokinetics and potential side effects is challenging but is addressed in two SRs on this topic in malnourished children ${ }^{14,15}$.

Arguments framing the usage of antibiotics for malnourished infants U6M include the higher mortality rates in this population ${ }^{16}$ and the higher prevalence of community-acquired bacteraemia in infants compared to older children amongst paediatric hospital admissions ${ }^{17}$. Also important are the costs of antibiotic use, both short-term financial costs, but also longer-term family and societal costs, with increasing use contributing to antimicrobial resistance ${ }^{18}$. 
215 In the management of 'SAM' in children over 6 months, a recent MA and comment on two 216 RCTs assessing the efficacy of oral amoxicillin compared to placebo reported a $3 \%$ increase in 217 survival with antibiotic treatment with amoxicillin ${ }^{19}$, whilst the individual trials noted an 218 increased rate of MUAC gain with amoxicillin ${ }^{20}$, improved rate of recovery and decreased risk of 219 transfer to inpatient care ${ }^{21}$. An older RCT assessed the efficacy of two days of intramuscular 220 ceftriaxone in comparison to five days of oral amoxicillin and suggested benefits in terms of 221 growth, recovery rate and case fatality rate in the ceftriaxone treated group, but this was not 222 statistically significant ${ }^{22}$.

223

224 The only study to include infants U6M (as well as those over 6 months) with 'SAM' examined 22512 month mortality with or without six months of co-trimoxazole prophylaxis after inpatient 226 admission for 'SAM'. This found no evidence of mortality or growth benefits ${ }^{23}$.

227

With regard to inpatient IV therapy for 'complicated SAM', Williams \& Berkley identified one interventional trial from 1996 and argue that current recommendations are based on no supporting evidence for either the type and duration of antibiotics ${ }^{15}$.

In the pre-term population, one study provides evidence of a role for erythromycin in establishing exclusive breastfeeding (EBF) in pre-term infants ${ }^{24}$, likely secondary to its gastrointestinal prokinetic effects (a potential avenue for a future package of interventions in this group). Indeed, there is increasing interest in the potential roles of macrolides in reducing childhood mortality. A cluster-randomised trial based in Tanzania, Malawi and Niger reported in 2018 an overall reduction of mortality by $13.5 \%$ in those communities receiving twice-yearly mass administration of azithromycin compared to those receiving placebo. Of particular note is that the largest reductions in mortality were seen in the infants 1-5 months group (nutritional status not reported) and in the most disadvantaged communities ${ }^{25}$.

\section{Safety}

No study addressed the safety profile of oral amoxicillin or first-line parental antibiotics in malnourished infants U6M. Co-trimoxazole prophylaxis was associated with an increased risk of neutropenia (grade 4), but age-specific effects were not reported ${ }^{23}$.

Williams \& Berkley's systematic review addressed the safety profiles of antibiotics used in the included studies, showing there was not a "significant rate of adverse effects documented in antibiotic intervention group (s)", but they do raise safety concerns about the currently recommended seven day course of gentamicin in the 'SAM' population, given its known renal toxicity, uncertain pharmacokinetics in the 'SAM' population and inability to monitor renal function and serum concentrations in many low-income settings ${ }^{15}$.

\section{Summary}


255 Current evidence, high mortality rates, higher rates of bacteraemia in infants than older children 256 and lower specificity of clinical signs for serious infections than in older age groups make

257

258

259

260

261

262

263

264

265

266

267

268

269

270

271

272

273

274

275

276

277

278

279

280

281

282

283

284

285

286

287

288

289

290

291

292

293

294 divergence from current guidelines difficult to justify for infants U6M.

Urgent research is required on this topic, especially for those infants who appear clinically stable and for whom risks and costs of routine antibiotic use may outweigh potential benefits. As one SR comments "given that these antibiotics have side-effects, costs, and risks as well as benefits, their routine use needs urgent testing...there is sufficient equipoise for placebo controlled $R C T s . "{ }^{26}$ The potential roles for macrolide antibiotics in vulnerable populations, particularly in the context of global increases in antimicrobial resistance, also require further evaluation. Mass antibiotic distribution using azithromycin may become policy in some low resource settings following recent trial and risks relating to antimicrobial resistance will need careful monitoring.

\section{Deworming}

Given limited mobility and the recommendation for EBF up to 6 months of age, it is often assumed that helminth burden is acquired later in infancy. However, evidence suggests that helminth acquisition may occur in infants $\mathrm{U}^{2} \mathrm{M}^{27-29}$. Whether or how this affects severe malnutrition at this age has not been investigated. Furthermore, anti-helminthic agents are not typically licensed for use in infants U6M.

We identified four MAs of relevance in the child population, three controlled trials in children with severe malnutrition (one which includes a sample of infants U6M) and one RCT that studied deworming in breastfeeding mothers.

\section{Efficacy}

In children over 6 months, the benefits of mass deworming are debatable, with the included MAs providing evidence that it offers no benefit in terms of mortality, nutritional status or cognition (GRADE Low/Moderate) ${ }^{30-33}$, although based on trials carried out in heterogenous populations with differing disease prevalence, age profiles and with nutritional status. Among individual studies, in malnourished pre-school aged children, one cluster-randomised trial in India showed significant improvements in weight gain amongst stunted and wasted infants treated with albendazole $(p<0.0001)^{34}$, whereas an RCT amongst 222 children under 5 years in the Democratic Republic of Congo showed negative impacts of mebendazole treatment on weight, height and MUAC gain (p-values $0.002,0.028$ and 0.012 respectively) ${ }^{35}$. More recently, in Malawi, a cluster-randomised trial of a package of interventions, that included deworming as a component, at discharge from supplementary feeding programmes for 'moderate acute malnutrition (MAM)' showed no significant impact on rates of 'MAM' relapse at 12-month follow-up ${ }^{36}$. 
295 Relevant to malnourished infants U6M, we identified one RCT that looked at infant outcomes 296 with albendazole treatment of breastfeeding mothers, showing a substantial mean difference gain 297 of 0.5 (95\% CI 0.2-0.8, $\mathrm{p}=0.003)$ in length-for-age $\mathrm{Z}$ score (LAZ) in infants of treated mothers 298 who had stool smears positive for helminth infections ${ }^{37}$.

299

300 Safety

301 Deworming treatment was associated with no adverse effects in included studies. WHO

302 recommend deworming from the age of 12 months $^{38}$. This is because of the presumed

303 epidemiology of helminth infections and although there is less safety data there are no specific 304 additional safety concerns in younger infants ${ }^{39}$.

305

306

307

308

309

310

311

312

313

314

\section{Summary}

There is no evidence to support introduction of routine deworming in infants U6M based on current evidence.

There is some evidence for deworming in breastfeeding mothers of malnourished infants U6M that requires further evaluation.

315 Vitamin A deficiency is a known cause of xerophthalmia and blindness and is associated with 316

317 increased mortality from diarrhoeal disease and measles. The most recent estimate of the prevalence of vitamin A deficiency amongst children aged 6-59 months in low- and middleincome countries is $29 \%$, ranging from $48 \%$ in sub-Saharan Africa to $6 \%$ in East \& Southeast Asia and Oceania, and contributes to $1.7 \%$ of all-cause mortality ${ }^{40}$. High quality epidemiological studies focusing on vitamin A profiles amongst infants or children with severe malnutrition are lacking. Breastfeeding has been shown to be a protective factor for xeropthalmia ${ }^{41}$.

322

323

We identified five MAs across all populations and two RCTs recruiting only children with

324 'SAM'. There was significant variation in dose and dosing regimen. 'High dose' ranged from 50,000-200,000IU in children over 12 months, from 25,000-100,000IU in infants under 12 months and from 2000-10,000IU in LBW. The most frequent 'low dose' was $5000 \mathrm{IU}$ in infants and children.

\section{Efficacy}

330 In the U6M population, neither MA identified any impact of vitamin A on mortality (GRADE Moderate/High $)^{42,43}$. No impact was noted on diarrhoea point prevalence in one of these (GRADE - Moderate) $)^{42}$. In the child population over the age of 6 months, one MA reported there 
334 and diarrhoea-associated mortality by $12 \%$ (GRADE - High) and of diarrhoea incidence by $15 \%$ 335 (Grade - Low) ${ }^{44}$.

336

337

338

339

340

341

342

343

344

345

346

347 Safety

348 Adverse effects were noted in both infant and child populations. Vitamin A supplementation was 349

350

351

352

353

354

355

356

357

358

359

360

361

362

363

364

365

366

367

368

369

370

371

372

373

In VLBW infants, a MA shows a similar level of reduction in all-cause mortality but this is not statistically significant (GRADE - Moderate) ${ }^{45}$. MA evidence of maternal post-partum vitamin A supplementation reported no benefit in terms of infant morbidity or mortality outcomes (GRADE - Very Low/Low $)^{46}$.

Among children 0-72 months of age with 'MAM', one RCT of single high dose of vitamin A compared to placebo ${ }^{47}$ reported increases in annual weight gain (Mean Difference $0.91 \mathrm{~kg}$, $\mathrm{p}=0.029$ ) and in annual MUAC gain (Mean Difference $1.29 \mathrm{~cm}, \mathrm{p}=0.012$ ) with but there seems to be no benefit of high dose supplementation compared to low dose in other RCTs $\mathrm{s}^{47-49}$. shown to be associated with a 1.5-3 times increased risk bulging of the anterior fontanelle 48-72 hours after first dosing. In all cases this resolved spontaneously and was associated with no neurological sequelae (GRADE - High) ${ }^{42,43}$. A two times increased risk of one or more episode of vomiting on commencing supplementation was noted in infants and child between the ages of 6-72 months (GRADE - Moderate) ${ }^{44}$, and on subgroup analysis in two RCTs there was some evidence of an elevated risk of diarrhoea in children of 6-60 months age without 'SAM'50 or with high-dose vitamin A in 'malnourished pre-school children without oedema' ${ }^{47}$.

\section{Summary}

Low-dose supplementation shows the potential for significant benefit in terms of mortality and diarrhoea incidence in deficient populations and in such settings should be given. However, outside of such situations of specific clinical need, routine use cannot be currently recommended given strong evidence of mild to moderate safety concerns.

More research on which populations/individuals do and which do not need extra vitamin A would be valuable.

\section{Vitamin D}

Vitamin D has diverse effects, being involved in calcium homeostasis, immune modulation, cell metabolism and growth. Global worldwide estimates of vitamin D deficiency in unsupplemented breastfed infants is $76 \%(18-82 \%)^{51}$.

Our search identified three MAs across infants, children and mothers and 13 RCTs across all populations. Six (one MA and five RCTs) of the included studies focused on serum vitamin D sufficiency as the outcome of interest. These were included as evidence for safety ${ }^{52-57}$. Doses of 
374 vitamin D were heterogeneous across studies, varying from 200-1000IU in LBW, between

$375400 \mathrm{IU}$ daily and a 50,000IU bolus in infants U6M, between 402IU daily and 200,000IU as a

376 single bolus in children, and from 1200-5000IU in breastfeeding mothers.

377

378

379 The only RCT, conducted in the urban setting in India, to supplement breastfed infants U6M, 380 either directly orally or by supplementing breastfeeding mothers orally, showed no significant 381 difference in weight, length or head circumference between vitamin $\mathrm{D}$ and placebo. However, 382 the mean number of days with respiratory or diarrhoeal illness was reduced by 33.5 days by 9 383 months of life $(\mathrm{p}<0.05)$ in infants supplemented with vitamin D orally ${ }^{58}$.

384

385

386

387

388

389

390

391

392

393

394

395

396

397

398

399

400

401

402

403

404

405

406

407

408

409

410

411

$412 \mathrm{LBW}^{68}$, the current WHO recommendations for LBW of 6 months supplementation can

In children over 6 months, one recent RCT carried out in 'uncomplicated SAM' in Pakistan was identified. Children received either 2 high doses of vitamin D or placebo with follow-up at 8 weeks. This study showed significant anthropometric effects in those receiving vitamin $\mathrm{D}$, with increases in weight-for height $\mathrm{z}$ score (WHZ)/weight-for-length $\mathrm{z}$ score (WLZ) (adjusted mean difference: $1.07 ; 95 \%$ CI: $0.49,1.65, \mathrm{P}<0.001$ ), and significant improvements across multiple developmental indices (gross motor, fine motor and language) ${ }^{59}$. In MAs of children under 5 years, no impact was noted on growth metrics, incidence of pneumonia (GRADE - Moderate), recovery time from pneumonia (GRADE - Low) and pneumonia-specific (GRADE - Very Low) and all-cause mortality (GRADE - Low) rates ${ }^{60-62}$.

In VLBW/LBW infants, vitamin D supplementation resulted in increases in all growth metrics (height, weight, MUAC) in two RCTs ${ }^{63,64}$ but follow-up of one of these studies at 3-6 years showed no lasting difference between groups ${ }^{65}$ and one RCT in extremely pre-term infants (2327 weeks gestation) showed no impact in terms of mortality ${ }^{66}$.

Two RCTs of maternal vitamin D supplementation showed 13\% increased prevalence of reported EBF at 6 months, a mean of 28 fewer days of respiratory and diarrhoeal illness by age 9 months ( $\mathrm{p}<0.01$ ), but no impact on infant growth ${ }^{58,67}$.

\section{Safety}

No adverse effects noted with vitamin D supplementation in any of the included studies.

\section{Summary}

Vitamin D supplementation is safe at doses reviewed within this report with evidence of efficacy in terms of growth in children over 6 months with 'uncomplicated SAM' and LBW infants, reduced morbidity in children and through maternal supplementation, potential roles in sustaining EBF. Given the fact that a considerable proportion of infants U6M were born at 
413 reasonably be followed in nutritional programming for malnourished infants U6M where birth

414 weight is unknown.

415

416 Further trials of vitamin D in malnourished infants U6M who are not LBW are warranted. There 417 are also questions about the optimum dose, duration and mode of delivery.

\section{Iron}

Iron has been implicated not just in haemoglobin synthesis but also in muscular, neurological and immune development ${ }^{69}$. However, debate continues around whether iron deficiency is protective of malaria and conversely whether iron excess increases risk of severe malaria ${ }^{70}$. Further concerns exist as to where iron supplementation is implicated in increased risk of bacterial infections in newborns ${ }^{71}$, risk of diarrhoea in infants and children, a change in gut flora and increased gastrointestinal inflammation and subsequent morbidity ${ }^{72}$.

The global burden of anaemia in children and infants is estimated to be $41.8 \%{ }^{73}$ and amongst the 'SAM' population, two studies from India estimate the prevalence of severe anaemia in the child 'SAM' population between 52-67.3\%, with a microcytic predominance ${ }^{74,75}$. Most of an infant's iron stores are endowed by the time of birth at term gestation with little derived from breast milk $^{76}$. This puts LBW infants at increased risk of iron deficiency, even if exclusively breastfed $^{77}$.

Our search identified eight MAs and five RCTs in pre-terms, infants and children but no articles specifically in malnourished populations. Significant heterogeneity was noted in terms of dosing schedule and outcomes assessed. Dose ranges were $2-4 \mathrm{mg} / \mathrm{kg}$ in LBW, $7.5-10 \mathrm{mg} /$ day in infants U6M and from $<12.6-150 \mathrm{mg} /$ day in children, although differing iron formulations were used with differing bioavailability of elemental iron. The most common dosing was $2 \mathrm{mg} / \mathrm{kg}$.

442

\section{Efficacy}

In children, of the two included MAs reporting on mortality, both generated insufficient data on which to estimate mortality ${ }^{70,78}$. All four MAs in both pre-terms and children showed iron supplementation to be associated with an increase in mean haemoglobin concentration (GRADE High or Moderate where reported) ${ }^{77-80}$. Amongst infants, one RCT in Sweden and Honduras reported no impact on weight gain, but in sub-group analyses reported reduced length gain in Swedish infants 4-9 months of age and in Honduran non-anaemic infants ${ }^{81}$. Psychomotor development in infants U6M was found to be significantly improved in the iron supplemented group in one $\mathrm{MA}^{82}$ but a further two RCTs of multiple micronutrients not included in this MA showed opposite effects in mean time to walking unassisted in subgroups analysing iron 
452 In children, three MAs showed inconsistent effects of iron on growth with one MA (wide age 453 range from infants to $>5$ years) suggesting small benefits in terms of weight-for-age (WAZ) but 454 reductions in some developed-setting subgroups in HAZ and rate of length gain ${ }^{85}$, one MA 455 showing no effect on growth in children 2-5 years (GRADE - Very Low) ${ }^{79}$, and one showing 456 mild increases in HAZ and no impact on WAZ (5-12 years) ${ }^{80}$. There was evidence of improved 457 cognitive performance in two MAs in those supplemented with iron from ages 2-12 years 458 (GRADE - Very Low, where reported) ${ }^{79,80}$.

459

460

461

462

463

464

465

466

467

468

469

470

471

472

473

474

475

476

477

478

479

480

481

482

483

484

485

486

487

488

489

490

491

In LBW infants, the included MA ${ }^{77}$ identified only one poor-quality RCT, out of 13 included studies reporting on growth, that showed improvements in growth ${ }^{77}$ and a subsequent RCT has shown no benefit in terms of growth ${ }^{86}$. This MA did not identify any studies comparing iron supplementation to placebo for neurodevelopmental outcomes and one study was identified that showed no difference in neurodevelopment between high- and low-dose iron but a higher incidence of an abnormal neurological examination at 5 years of age with late-onset supplementation of iron ${ }^{77}$. Child behaviour but not intelligence scores were reported in one RCT as significantly better at seven-year follow-up of LBW infants supplemented with iron from birth compared with unsupplemented infants ${ }^{87}$.

\section{Safety}

A MA of iron supplementation to children under 18 years in malaria-endemic areas showed no impact on overall malaria incidence and indeed $10 \%$ relative risk reduction of severe malaria was noted with iron supplementation (GRADE - High) ${ }^{70}$. Iron was well tolerated in 10 of the 11 studies that documented adverse effects with only one MA noting an $11 \%$ increased risk of diarrhoea in iron supplemented groups $(\mathrm{p}=0.04)^{88}$.

\section{Summary}

There is a lack of any strong evidence for benefits of iron supplementation in terms of mortality and morbidity but evidence of increased haemoglobin status and some neurodevelopmental benefits across age groups. Concerns, such as those raised in the WHO guidelines on iron supplementation in children ${ }^{89}$, exist about potential negative impacts of iron supplementation on growth, infection risk and malaria risk in malaria-endemic settings where regions where malaria prevention and treatment systems are not in place and/or where children are already iron replete ${ }^{90}$. Routine use for all malnourished infants U6M cannot therefore be recommended, but there can be exceptions for specific individuals and/or populations for treatment of iron deficiency.

Further trials are investigating potential alternatives to simple iron salts and ways to target iron therapy.

\section{Zinc}


492 Zinc has received much attention for its role in the management of acute diarrhoea, but a

493 plurality of roles in cell growth, immunity and metabolism continue to be identified ${ }^{91}$. Estimating

494 prevalence of zinc deficiency is challenging for both logistical and assay availability reasons but

495 recent estimates suggest $17.3 \%$ of the world's population is at high risk of deficiency with

496 prevalence of inadequate zinc intake correlated to prevalence of childhood stunting ${ }^{92}$.

497

Our search identified a vast literature on zinc supplementation that proved challenging to

499 summarise. We identified 24 relevant articles: two RCTs in infants and children with 'SAM' and

500 four further RCTs in children over 6 months of age; one SR and seven RCTs in LBW infants;

501 and two RCTs and nine MAs in non-malnourished infants and children. No articles were

502 identified that looked at maternal post-natal zinc supplementation. In children, the most common

503 zinc dosage was $20 \mathrm{mg}$ /day (range 5-40mg) with high dose usage in some RCTs up to

504 $6 \mathrm{mg} / \mathrm{kg} /$ day. In infants under 12 months, doses ranged from 1.78-20mg/day and in LBW from 5-

505 $10 \mathrm{mg} /$ day or $2 \mathrm{mg} / \mathrm{kg} /$ day.

506

507

508

509

Efficacy

510

Within the 'SAM' population, we identified two RCTs in infants U6M and children over 6 months of age showing a reduced total number of total infectious episodes (13 days fewer in the

511 supplemented population over 90 -days of follow-up, $\mathrm{p}<0.025)$, reduction in number of diarrhoeal

512 episodes ( 0.6 less than control group, $\mathrm{p}=0.04$ ) at 8 weeks follow-up following admission for

513 diarrhoea, and evidence of slight length gain $(4.4 \mathrm{~mm}$ greater compared to control group at 8

514 weeks follow-up, reported as $\mathrm{p}<0.05$ ) but not weight gain ${ }^{93,94}$. In children over the age of 6

515 months with 'SAM', two further RCTs identified significant increased anthropometric indices associated with zinc supplementation (one in length, two in weight and one in MUAC) ${ }^{95,96}$. In one of these trials, examining 10mg zinc daily from admission to hospital until 90 days postdischarge, a significant $11 \%$ reduction in in-hospital mortality in zinc-supplemented children was also reported ${ }^{95}$ and in the other, there was reduced number of morbid episodes (cough, diarrhoea, fever, vomiting) in stunted children ${ }^{96}$. One further RCT showed no significant anthropometric

521

522 impacts of high-dose compared to low-dose zinc $^{97}$.

\section{3}

In a MA of the infant U6M population as a whole, no impact on all-cause mortality or diarrhoea duration or presence at day 7 was demonstrated (GRADE - Very Low and Low respectively) ${ }^{98}$. In combination with the child population a $13 \%$ reduction in pneumonia incidence (GRADE -

526 Low) ${ }^{99}$ and slightly improved WAZ and WLZ (pooled effects +0.06 and +0.05 respectively) but not MUAC were found ${ }^{91}$. A single RCT showed that zinc when used as an adjunct to treatment

528 for neonatal sepsis resulted in significantly reduced mortality and improved mental development at 12 months ${ }^{100}$.

529

530

Among children aged over 6 months, one MA showed an 18\% reduction in all-cause mortality in 531 those over 12 months ${ }^{101}$, but two other MAs demonstrated no effect on mortality (GRADE - 
532 High and Very Low $)^{98,102}$. Furthermore, three MAs demonstrated a reduction in incidence and 533 duration of all-cause diarrhoea (GRADE - Moderate) $)^{98,101,102}$, and one MA identified a

534 significant reduction in mortality when used as an adjunct to treatment for severe pneumonia ${ }^{103}$.

535 A further four MAs noted improved, albeit across different anthropometric indices, with zinc

536 supplementation ${ }^{101,104-106}$, with more marked improvements when supplemented after two years

537 of age ${ }^{106}$. No impacts on mental or psychomotor development were demonstrated by one MA

538 (GRADE - Moderate) ${ }^{107}$.

539

540 In the LBW population, concerning indices of growth, one SR of three trials identified no impact

541 of zinc supplementation on length or weight ${ }^{108}$, but four of five RCTs identified by our search

542 demonstrate significant effects in terms of length and weight gain ${ }^{109-113}$. The same SR included

543 one trial that showed no benefit in terms of mortality, whereas our search identified two RCTs

544 suggesting a reduction in mortality with zinc supplementation by $58-68 \%{ }^{111,114}$. Concerning

545 morbidity outcomes, one SR identified two trials showing no overall impacts on number of

546 diarrhoeal illnesses but fewer days of diarrhoea following cessation of breastfeeding and one trial

547 showing no impact on acute lower respiratory tract infection incidence ${ }^{108}$. Furthermore, one RCT

548 showed a reduction in combined neonatal morbidities (late-onset sepsis, necrotising enterocolitis,

549 bronchopulmonary dysplasia etc) with zinc supplementation ${ }^{111}$. Finally, one RCT reporting on

550 neurodevelopmental outcomes showed increased alertness and attention at term corrected

551 gestational age and reduced hyper-excitability at three months follow-up in zinc supplemented

552 infants $^{115}$.

553

554 Safety

555 Adverse effects and safety concerns associated with zinc supplementation were poorly reported

556 with only 10 of 24 included articles explicitly mentioning this. Of articles that documented

557 adverse effects or none, one RCT in Bangladesh, of 141 children 6 months -3 years old with

558 'SAM' identified a 4.5 times increased mortality with high-dose $(6.0 \mathrm{mg} / \mathrm{kg}$ for $15+$ days $)$

559 compared to low-dose ( $1.5 \mathrm{mg} / \mathrm{kg}$ for 15 days) zinc supplementation $(\mathrm{p}=0.03)^{97}$ and two MAs in

560 infants and children identified a significant $29-57 \%$ increased risk of one or more episodes of

561 vomiting upon commencement of zinc supplements (GRADE - High and Moderate) $)^{98,102}$.

562

563 Summary

564 Consistent evidence across age groups exists of zinc supplementation being associated with

565 reduced morbidity and improved anthropometry, whilst mortality and neurodevelopmental

566 impacts are more unclear. Zinc should not be supplemented as a high-dose, given mortality

567 concerns, and its tolerability should be considered in the context of vomiting risk. Zinc should be

568 supplemented as per diarrhoea guidelines for all severely malnourished infants U6M with

569 diarrhoeal illnesses ${ }^{116}$. In cases where severely malnourished infants U6M are not affected by

570 diarrhoea, in the absence of further evidence, we suggest that $2 \mathrm{mg} /$ day (1 recommended daily

571 allowance ${ }^{117}$ ) of zinc be supplemented with other micronutrients in regions where zinc 
572 deficiency has been documented. This is because breastmilk zinc concentrations have been

573 shown to be insufficient in zinc deficient mothers ${ }^{118,119}$.

574

575 Research is urgently needed to establish zinc requirements for malnourished infants U6M and

576 the fact that there is some evidence of mortality benefit when supplemented over an extended

577 period suggests that randomised trials are warranted in this age group.

578

579 Folic acid

580 Folic acid is essential for DNA synthesis and repair, erythropoiesis and cellular metabolism and

581 deficiency is clinically associated with megaloblastic anaemias and foetal neural tube defects ${ }^{120}$.

582 Characterising the burden of folic acid deficiency in children is challenging given differing

583 definitions, but, amongst pre-school children in sub-Saharan Africa, estimates range from 0-

584

585

586 $8.5 \%$ with the exception of one study in Gambia which estimated a $24 \%$ prevalence ${ }^{121}$.

587

Folic acid has garnered much attention regarding pre-conceptual and pre-natal supplementation,

588 but our search identified comparatively little with regard to child or post-natal supplementation:

589 no MAs in infants and children and 10 RCTs across pre-terms, infants and both well- and

590 malnourished children. Folic acid supplementation varied from 50-250 $\mu \mathrm{g} /$ day among trials in

591

592 Efficacy

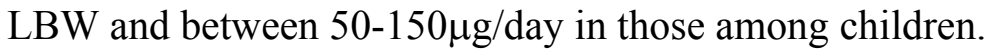

593 Folic acid supplementation was shown in two RCTs in infants and children to have no impact on 594 mortality $^{122,123}$. In children over 6 months of age, two RCTs showed reduced incidence of acute 595 diarrhoeal disease and lower respiratory tract infection ${ }^{123,124}$ and one RCT showed increased total

596

597

598

599

600

601

602

603

604

605

606

607

608

609

610 weight gain and WAZ scores with folic acid supplementation compared to placebo ${ }^{125}$.

Amongst LBW infants, of three RCTs included all showed no impact of folic acid on weight gain, one noticed length gains in a subgroup of infants of birthweight $>1750 \mathrm{~g}$, and one showed no improvement in infectious disease incidence or haemoglobin status ${ }^{126-128}$.

\section{Safety}

A safety debate around folic acid supplementation has centred on its usage in malaria-endemic settings as malaria parasites can utilise exogenous folate during co-administration with sulfadoxine/pyrimethamine (SP) (a folate antagonist used in the prevention and treatment of malaria). In a paired set of RCTs studying folic acid supplementation amongst children 1-36 months, the Tanzanian trial was stopped early because of increased adverse events and hospital admissions in the supplemented arm $^{122}$ but this was not replicated in the Nepalese study ${ }^{123}$. Subsequent post-hoc analysis of the Tanzanian study showed adverse events were not associated with SP co-administration. Three further RCTs looking at SP and folic acid co-administration 
611 showed some evidence of parasitological but not clinical treatment failure with SP and folic acid 612 co-administration ${ }^{129-131}$.

613

614 Folic acid was well tolerated in other studies with the exception of one RCT amongst Indian

615 children that showed a two times increased incidence of persistent diarrhoea in the supplemented 616 group ${ }^{124}$, something that was not replicated in the two other RCTs reporting on diarrhoea 617 incidence.

618

619

Summary

620 There is limited evidence of benefit in the child population in terms of morbidity and growth and 621 therefore this is not recommended as a routine intervention for malnourished infants U6M. Any 622 benefits that may exist are not consistent across age groups. Safety in a malaria endemic setting 623 remains uncertain but is less concerning given SP is no longer routinely used for the treatment of 624 malaria. Safety of folic acid supplementation should be considered in areas where SP is used for 625 Seasonal Malarial Chemoprophylaxis (SMC) or Intermittent Preventive Treatment in pregnancy 626 (IPTp).

627

628 Further studies investigating the role of folic acid in malnourished infants U6M are warranted 629 but the evidence presented does not identify this as a priority area for research.

630

631

\section{Maternal supplementation of macronutrients or multiple micronutrients}

632 Given the nutritive demands on the breastfeeding mother, maternal micronutrient and

633 macronutrient supplementation during breastfeeding is seen as a potentially promising approach

634 to improving both maternal and infant nutritional status and multiple micronutrient and

635 macronutrient supplementation has received increasing attention in recent years.

636

637

Our search identified four MAs and one RCT covering the topics of post-natal multiple

638 micronutrient and polyunsaturated fatty acid (PUFA) supplementation. Articles pertaining to maternal supplementation with single micronutrients are included in the section relevant to that

640 micronutrient. Within these included studies the post-natal period was inconsistently defined but 641 supplementation typically occurred within 2 weeks of delivery and up to 4 months post-partum.

642

643 Efficacy

644 Maternal post-natal multiple micronutrient supplementation was associated with no quantitative 645 evidence of improvement in infant and child mortality or morbidity outcomes ${ }^{132}$. One of the 646 three MAs looked at PUFA supplementation compared to placebo to breastfeeding mothers 647 postnatally and demonstrated no benefit in terms of infant length, weight and head circumference 648 (GRADE Moderate) ${ }^{133}$. These results of no significant growth effects were supported in the two 649 other MAs but the population included supplementation during both gestation and lactation and 650 no postnatal subgroup analysis was presented ${ }^{134,135}$. A statistically significant improvement was 
651 noted in indices of child attention beyond 24 months of age in the first of these MAs (GRADE 652 Low $)^{133}$. An RCT of maternal calorie supplementation in conjunction with a breastfeeding 653 support intervention showed no improvement in WAZ or LAZ but increased infant breast milk 654 intake and a two times increase in EBF (likely secondary to the support intervention) was 655 demonstrated ${ }^{136}$.

656

657 Safety

658 No clinically detectable adverse effects were reported in any of the included studies.

659

660

\section{Summary}

661

662 We found insufficient evidence of the benefits of maternal supplementation to infants to justify

663 routine use in current programming for malnourished infants U6M. However, potential benefits 664 to the mother, not included in this review, should be considered and evaluated in more detail in further research to inform decisions in this area.

\section{Oral Rehydration in severe malnutrition complicated by diarrhoea}

668 Diarrhoea affects a large proportion of children with severe malnutrition admitted to inpatient care. Studies in sub-Saharan Africa identify the prevalence of diarrhoea at admission to hospital with 'SAM' at 49-67.3\%, with its presence being associated with increased inpatient mortality rates $(19 \% \text { vs } 9 \% \text {, OR } 2.5)^{137,138}$. The current WHO guidelines for the management of diarrhoea

672 in 'SAM' in children over 6 months recommend oral rehydration rather than intravenous

673 rehydration, unless shock exists, due to the theoretical concerns of causing fluid overload and precipitating heart failure ${ }^{139}$. ReSoMal is the recommended form of ORS in 'SAM' complicated by diarrhoea, except in cases of cholera. It differs from the standard WHO hypo-osmolar ORS in having a lower sodium, higher potassium and higher glucose concentrations as well as a higher osmolality. The comparative compositions are presented in Table 4. The rationale for these differing compositions being that severely malnourished children would be predisposed to fluid retention due to their already high intracellular sodium concentrations, again risking fluid

681 overload and heart failure ${ }^{7}$, although the evidence underlying this is contentious ${ }^{140}$.

683

684

\section{Table 4: Compositions of commonly used oral rehydration solutions $(\text { ORS })^{7}$}

685

Infants in the first few months of life are at increased risk of dehydration during diarrhoea

686 episodes because of their relatively higher body surface area and difficulty drinking enough to

687 match losses. They are also more susceptible to water and sodium retention because of immature renal sodium and water excretion mechanisms both in the kidney and in hormonal control ${ }^{141-143}$. Theoretically, this may reduce the risk of hyponatraemia during rehydration with lower 690 osmolarity ORS compared with older children. The 2013 WHO SAM guidelines update makes no comment on how the rehydration of infants U6M with diarrhoea should be managed. 
691 However, there is explicit mention, albeit concerning their nutritional management, that infants 692 'should not be given undiluted F-100 at any time (owing to the high renal solute load and risk of 693 hypernatraemic dehydration) ${ }^{7}$; a factor that should be considered when thinking about oral 694 rehydration in this age group. There appears to be widespread consensus that standard WHO 695 ORS should be used in the rehydration of infants U6M without 'SAM' and that breastfeeding 696 should be continued throughout the episode of acute gastroenteritis ${ }^{7,144-146}$.

697

698 Our search focused on the evidence for the usage of ReSoMal for oral rehydration in severe 699 malnutrition complicated by diarrhoea. Comparisons of other formulations of ORS, polymer700 based ORS and intravenous rehydration strategies were considered beyond the scope of this 701 review.

702

703

704

705

We identified one recent $\mathrm{SR}^{136}$ that included two RCTs in the Asian inpatient setting comparing ReSoMal to WHO ORS in children over 6 months, which were assessed to be of low risk of bias $^{147,148}$. No articles looking at ReSoMal in infants U6M were identified.

706

707 Efficacy

708 Both studies reported on time to rehydration, with Alam et al. (2003) showing no difference 709 between ReSoMal and ORS and Kumar et al. (2015) reporting a shorter time to rehydration with 710 ReSoMal (16.1 hours vs 19.6 hours $\mathrm{p}=0.036$ ). Stool frequency and number of patients requiring

711 IV fluids after attempting oral rehydration was shown to be similar between treatment groups in 712 both studies. Only Alam et al. (2003) reported on mortality, reporting no deaths. Neither study

713 reported on anthropometric or neurodevelopmental outcomes.

714

715 Safety

716 The primary outcome of the included SR was the occurrence of hyponatraemia. Alam et al 717 (2003) ReSoMal was associated with a higher incidence of severe hyponatraemia ( $\mathrm{Na}<120 \mathrm{mmol}$ 718 compared to an older WHO ORS formulation ( $5 \%$ versus $2 \%$,) a lower mean serum sodium at 24 719 and 48 hours ( $<0.01$ and $<0.001$ respectively) and with one episode of hyponatraemic seizures 720 ( $\mathrm{n}=130)$. Similarly, Kumar et al. (2015), comparing ReSoMal with standard ORS, showed

721 ReSoMal to be associated with increased incidence of hyponatraemia ( $15.4 \%$ vs $1.9 \%, \mathrm{n}=110)$.

722 Alam et al. (2003) reported there to be no difference in frequency of fluid overload between 723 groups.

724

725

\section{Summary}

There are no studies of ReSoMal in infants U6M. Limited evidence from inpatient studies of older children with 'SAM' suggests that ReSoMal is of similar efficacy in terms of rehydration to standard ORS but that there are significant safety concerns in terms of risk of hyponatraemia. On the basis of current evidence, and the fact that infants in the first few months of life are at increased risk of water and salt retention due to immature hormonal and renal excretion 
731

732

733

734

735

736

737

738

739

740

741

742

743

744

745

746

747

748

749

750

751

752

753

754

755

756

757

758

759

760

761

762

763

764

765

766

767

768

769

770

mechanisms, there is no reason to change current recommendations for use of ReSoMal in malnourished infants U6M. This age group may differ from older children in both risks and responses to treatment and is thus a priority area for clinical trials.

\section{Conclusions}

This review has collated, reviewed and summarised the evidence-base for a selection of common medical interventions (antibiotics, de-worming, infant micronutrient supplementation, maternal macro- and micro-supplementation and ReSoMal) that may be considered for use in infants U6M identified by current screening criteria as severely malnourished. A key finding is the lack of direct evidence for this population group. In its absence, we have identified evidence in closelyrelated populations, exploring consistency of effect in terms of both efficacy and safety. Even for these groups, including LBW infants and malnourished children over the age of 6 months, the evidence base is neither strong nor extensive. It does however allow us to make some tentative recommendations and establishes an initial evidence base from which policy discussions about best approaches to managing infants U6M with severe malnutrition can begin.

The scope of this review is deliberately broad, particularly in using a non-specific definition of severe malnutrition and broad age group categories to reflect current WHO subdivisions. The utility of this review is derived from it gathering a vast body of evidence of disparate interventions, populations and study outcomes which may help frame policy and programming discussions as well as future research. Given such breadth, it was not possible to perform a full systematic search strategy and MA for each intervention nor was it possible to do a comprehensive assessment of quality of evidence, something that would be warranted in the future. Guidance for programmers is urgently needed, and whilst we have presented tentative recommendations, the weak and disparate evidence-base would benefit from wider expert consultation and consensus beyond those directly engaged in this review.

It is notable that of included articles, most showed no effect of the investigated intervention and amongst those that did, the effects were small with broad confidence intervals. There is a lack of accurate global micronutrient profiling, partly due to technical difficulties in measurement and capacity for assessment in low-resource settings, and as a result, the majority of studies look at the impact of mass supplementation without knowledge of whether it is a nutrient deficient or replete population. Studies may therefore be underpowered to detect benefits at a population level and fail to detect important effects among specifically micronutrient deficient infants and children. In addition, on reviewing the doses and dosing regimens of included studies, there is significant heterogeneity in dosing between trials within age groups, let alone across age groups. This makes creating accurate estimates of effect challenging and leaves policy makers with difficulty as to how to interpret these null or marginal effects, and programmers uncertain as to what dosage to implement in the context of their specific population or sub-population. 
771 Little is known about micronutrient status and needs of infants U6M identified as malnourished.

772 Although it is likely that they fall somewhere between those of LBW infants and malnourished

773 children over 6 months of age, they may vary between those born LBW or not, or in relation to

774 maternal capacity to develop foetal pre-natal stores, and by exclusivity of breastfeeding. Given

775 this, we have presented the evidence for medical interventions in these two adjacent populations

776 groups; the implications of these findings on the population of malnourished U6M and how this

777 should shape future programming remains to be determined.

778

779 The review raises several key research and policy questions which warrant urgent discussion and

780 evaluation including: what is the micronutrient status of infants U6M with severe malnutrition

781 and what interventions might be effective in their recovery, what is the optimal oral rehydration

782 protocol for this age group, how might medical interventions practically be delivered alongside

783

784

785

786

787

788

789

790

791

792

793

794

795

796

797

798

799

800

801

802

803

804

805

806

807

808

809

810

811 supporting/re-establishing EBF and finally what interventions can safely form interim policy in the absence of direct evidence?

\section{Acknowledgements}

The authors also thank WHO (Department of Maternal, Newborn, Child and Adolescent Health and the Department of Nutrition for Health and Development) and the Gates Foundation for commissioning an update to this review, which was presented at a to a January 2019 Technical consultation on 'Research priorities to prevent, identify and manage young infants with growth failure in the first 6 months of life'

\section{References}

1 Institute for Health Metrics and Evaluation. Global Burden of Disease Results Tool. 2015.

2 Black RE, Victora CG, Walker SP, Bhutta ZA, Christian P, De Onis M, Ezzati M, Grantham-Mcgregor S, Katz J, Martorell R, Uauy R. Maternal and child undernutrition and overweight in low-income and middle-income countries. Lancet 2013; 382: 427-451. 3 Kerac M, Blencowe H, Grijalva-Eternod C, McGrath M, Shoham J, Cole TJ, Seal A. Prevalence of wasting among under 6-month-old infants in developing countries and implications of new case definitions using WHO growth standards: a secondary data analysis. Arch Dis Child 2011; 96: 1008-1013.

4 Grijalva-Eternod CS, Kerac M, Mcgrath M, Wilkinson C, Hirsch JC, Delchevalerie P, Seal AJ. Admission profile and discharge outcomes for infants aged less than $6 \mathrm{months}$ admitted to inpatient therapeutic care in 10 countries . A secondary data analysis. Matern Child Nutr 2017; : 1-11. 
8125 Mwangome M, Ngari M, Fegan G, Mturi N, Shebe M, Bauni E, Berkley JA. Diagnostic 813 criteria for severe acute malnutrition among infants aged under 6 mo. Am J Clin Nutr $814 \quad$ 2017; 105: ajcn149815.

8156 Mwangome M, Ngari M, Bwahere P, Kabore P, McGrath M, Kerac M, Berkley JA.

816

817

818 Anthropometry at birth and at age of routine vaccination to predict mortality in the first year of life: A birth cohort study in BukinaFaso. PLoS One 2019; 14: e0213523.

819 World Health Organization. Guideline: Updates on the Management of Severe Acute

820 Malnutrition in Infants and Children. Geneva, 2013

8 Lelijveld BN, Kerac M, Mcgrath M, Mwangome M, Berkley JA. A review of methods to detect cases of severely malnourished infants less than 6 months for their admission into

821 therapeutic care. ENN Online 2017. https://www.ennonline.net/mamicasedetectionreview.

823 Bhutta ZA, Berkley JA, Bandsma RHJ, Kerac M, Trehan I, Briend A. Severe childhood

824

825 malnutrition. Nat. Rev. Dis. Prim. 2017; 3: 17067.

10 ENN. Making Connections: Joint meeting of WaSt Technical Interest Group and MAMI Special Interest Group. 2018. https://www.ennonline.net/resources/makingconnections).

826

11 Tarry-Adkins JL, Ozanne SE. Mechanisms of early life programming: current knowledge and future directions. Am J Clin Nutr 2011; 94: 1765S-1771S.

828

829 Munirul Islam M, Arafat Y, Connell N, Mothabbir G, McGrath M, Berkley JA, Ahmed T,

830

831 Kerac M. Severe malnutrition in infants aged \&1t; 6 months-Outcomes and risk factors in Bangladesh: A prospective cohort study. Matern Child Nutr 2018; : e12642.

832 World Health Organization. Guidelines on optimal feeding of low birth-weight infants in

833

834 low- and middle-income countries. 2011.

835 Lazzerini M, Tickell D. Antibiotics in severely malnourished children: systematic review of efficacy, safety and pharmacokinetics. Bull World Heal Organ 2011; 89: 593-606.

837 Williams PCM, Berkley JA. Guidelines for the treatment of severe acute malnutrition: a

838 systematic review of the evidence for antimicrobial therapy. Paediatr Int Child Health 2018; 38: S32-S49.

840 ENN/UCL/ACF. The MAMI Project - Key findings and recommendations. F Exch 39 2010. https://www.ennonline.net/fex/39/mami.

842 Berkley JA, Lowe BS, Mwangi I, Williams T, Bauni E, Mwarumba S, Ngetsa C, Slack MPE, Njenga S, Hart CA, Maitland K, English M, Marsh K, Scott JAG. Bacteremia among Children Admitted to a Rural Hospital in Kenya. N Engl J Med 2005; 352: 39-47.

845 Ferri M, Ranucci E, Romagnoli P, Giaccone V. Antimicrobial resistance: A global emerging threat to public health systems. Crit Rev Food Sci Nutr 2017; 57: 2857-2876.

847

848 Million M, Lagier J-C, Raoult D. Meta-analysis on efficacy of amoxicillin in

849 uncomplicated severe acute malnutrition. Microb Pathog 2017; 106: 76-77.

20 Trehan I, Goldbach HS, Lagrone LN, Meuli GJ, Wang RJ, Maleta KM, Manary MJ. Antibiotics as Part of the Management of Severe Acute Malnutrition. N Engl J Med 2013;

850

851 368: $425-35$.

852

21 Isanaka S, Langendorf C, Berth? F, Gnegne S, Li N, Ousmane N, Harouna S, Hassane H, Schaefer M, Adehossi E, Grais RF. Routine Amoxicillin for Uncomplicated Severe Acute

853

854 Malnutrition in Children. N Engl J Med 2016; 374: 444-453.

22 Dubray C, Ibrahim SA, Abdelmutalib M, Guerin PJ, Dantoine F, Belanger F, Legros D, Pinoges L, Brown V. Treatment of severe malnutrition with 2-day intramuscular ceftriaxone vs 5-day amoxicillin. Ann Trop Paediatr 2008; 28: 13-22.

856 
858

859

860

861

862

863

864

865

866

867

868

869

870

871

872

873

874

875

876

877

878

879

880

881

882

883

884

885

886

887

888

889

890

891

892

893

894

895

896

897

898

899

900

901

902

903

Mturi N. Daily co-trimoxazole prophylaxis to prevent mortality in children with complicated severe acute malnutrition : a multicentre, double-blind , randomised placebocontrolled trial. Lancet Glob Heal 2016; 4: e464-e473.

24 Gokmen T, Oguz S, Bozdag S, Erdeve O, Uras N, Dilmen U. A controlled trial of erythromycin and UDCA in premature infants during parenteral nutrition in minimizing feeding intolerance and liver function abnormalities. J Perinatol 2011; 32: 123-128.

25 Keenan JD, Bailey RL, West SK, Arzika AM, Hart J, Weaver J, Kalua K, Mrango Z, Ray KJ, Cook C, Lebas E, O’Brien KS, Emerson PM, Porco TC, Lietman TM. Azithromycin to Reduce Childhood Mortality in Sub-Saharan Africa. N Engl J Med 2018; 378: $1583-$ 1592.

26 Alcoba G, Kerac M, Breysse S, Salpeteur C, Galetto-Lacour A, Briend A, Gervaix A. Do Children with Uncomplicated Severe Acute Malnutrition Need Antibiotics? A Systematic Review and Meta-Analysis. PLoS One 2013; 8: e53184.

27 Ghiwot Y, Degarege A, Erko B. Prevalence of intestinal parasitic infections among children under five years of age with emphasis on Schistosoma mansoni in Wonji Shoa Sugar Estate, Ethiopia. PLoS One 2014; 9: e109793.

28 Fonseca AM, Fernandes N, Ferreira FS, Gomes J, Centeno-Lima S, Centeno-Lima S. Intestinal parasites in children hospitalized at the Central Hospital in Maputo, Mozambique. J Infect Dev Ctries 2014; 8: 786-789.

29 Goto R, Mascie-Taylor CGN, Lunn PG. Impact of anti-Giardia and anthelminthic treatment on infant growth and intestinal permeability in rural Bangladesh: a randomised double-blind controlled study. Trans R Soc Trop Med Hyg 2009; 103: 520-529.

30 Welch VA, Ghogomu E, Hossain A, Awasthi S, Bhutta ZA, Cumberbatch C, Fletcher R, McGowan J, Krishnaratne S, Kristjansson E, Sohani S, Suresh S, Tugwell P, White H, Wells GA. Mass deworming to improve developmental health and wellbeing of children in low-income and middle-income countries: a systematic review and network metaanalysis. Lancet Glob Heal 2017; 5: e40-e50.

31 Taylor-Robinson DC, Maayan N, Soares-Weiser K, Donegan S, Garner P. Deworming drugs for soil-transmitted intestinal worms in children: effects on nutritional indicators, haemoglobin, and school performance. In: Taylor-Robinson DC (ed). Cochrane Database of Systematic Reviews. John Wiley \& Sons, Ltd: Chichester, UK, 2015 doi:10.1002/14651858.CD000371.pub6.

32 Clarke NE, Clements ACA, Doi SA, Wang D, Campbell SJ, Gray D, Nery S V. Differential effect of mass deworming and targeted deworming for soil-transmitted helminth control in children: a systematic review and meta-analysis. Lancet 2017; 389: 287-297.

33 Thayer WM, Clermont A, Walker N. Effects of deworming on child and maternal health: a literature review and meta-analysis. BMC Public Health 2017; 17: 830.

34 Awasthi S, Peto R, Pande VK, Fletcher RH, Read S, Bundy DAP. Effects of deworming on malnourished preschool children in India: an open-labelled, cluster-randomized trial. PLoS Negl Trop Dis 2008; 2: e223.

35 Donnen P, Brasseur D, Dramaix M, Vertongen F, Zihindula M, Muhamiriza M, Hennart P. Vitamin A supplementation but not deworming improves growth of malnourished preschool children in eastern Zaire. J Nutr 1998; 128: 1320-7.

36 Stobaugh HC, Bollinger LB, Adams SE, Crocker AH, Grise JB, Kennedy JA, Thakwalakwa C, Maleta KM, Dietzen DJ, Manary MJ, Trehan I. Effect of a package of

PeerJ reviewing PDF | (2019:09:41387:1:1:NEW 14 Apr 2020) 
908

909

910

911

912

913

914

915

916

917

918

919

920

921

922

923

924

925

926

927

928

929

930

931

932

933

934

935

936

937

938

939

940

941

942

943

944

945

946

947

948

949 health and nutrition services on sustained recovery in children after moderate acute malnutrition and factors related to sustaining recovery: a cluster-randomized trial. Am J Clin Nutr 2017; 106: 657-666.

37 Mofid LS, Casapía M, Aguilar E, Silva H, Montresor A, Rahme E, Fraser WD, Marquis GS, Vercruysse J, Allen LH, Blouin B, Razuri H, Pezo L, Gyorkos TW. A Double-Blind Randomized Controlled Trial of Maternal Postpartum Deworming to Improve Infant Weight Gain in the Peruvian Amazon. PLoS Negl Trop Dis 2017; 11: e0005098.

38 World Health Organization. WHO | Deworming in children. e-Library Evid. Nutr. Actions. 2019. https:/www.who.int/elena/titles/deworming/en/

39 Montresor A, Awasthi S, Crompton DWT. Use of benzimidazoles in children younger than 24 months for the treatment of soil-transmitted helminthiasis. Acta Trop 2003; 86: 223-32.

40 Stevens GA, Bennett JE, Hennocq Q, Lu Y, De-Regil LM, Rogers L, Danaei G, Li G, White RA, Flaxman SR, Oehrle S-P, Finucane MM, Guerrero R, Bhutta ZA, ThenPaulino A, Fawzi W, Black RE, Ezzati M. Trends and mortality effects of vitamin A deficiency in children in 138 low-income and middle-income countries between 1991 and 2013: a pooled analysis of population-based surveys. Lancet Glob Heal 2015; 3: e528e536.

41 Semba RD, de Pee S, Panagides D, Poly O, Bloem MW. Risk Factors for Xerophthalmia Among Mothers and Their Children andfor Mother-Child Pairs With Xerophthalmia in Cambodia. Arch Ophthalmol 2004; 122: 517.

42 Imdad A, Ahmed Z, Bhutta ZA. Vitamin A supplementation for the prevention of morbidity and mortality in infants one to six months of age. In: Bhutta ZA (ed). Cochrane Database of Systematic Reviews. John Wiley \& Sons, Ltd: Chichester, UK, 2016 doi:10.1002/14651858.CD007480.pub3.

43 Haider BA, Sharma R, Bhutta ZA. Neonatal vitamin A supplementation for the prevention of mortality and morbidity in term neonates in low and middle income countries. Cochrane Database Syst Rev 2017; 2: CD006980.

44 Imdad A, Mayo-Wilson E, Herzer K, Bhutta ZA. Vitamin A supplementation for preventing morbidity and mortality in children from six months to five years of age. In: Bhutta ZA (ed). Cochrane Database of Systematic Reviews. John Wiley \& Sons, Ltd: Chichester, UK, 2017 doi:10.1002/14651858.CD008524.pub3.

45 Darlow BA, Graham PJ, Rojas-Reyes MX. Vitamin A supplementation to prevent mortality and short- and long-term morbidity in very low birth weight infants. Cochrane Database Syst Rev 2016; : CD000501.

46 Oliveira JM, Allert R, East CE. Vitamin A supplementation for postpartum women. Cochrane Database Syst Rev 2016; 3: CD005944.

47 Donnen P, Dramaix M, Brasseur D, Bitwe R, Vertongen F, Hennart P. Randomized placebo-controlled clinical trial of the effect of a single high dose or daily low doses of vitamin A on the morbidity of hospitalized, malnourished children. Am J Clin Nutr 1998; 68: $1254-60$.

48 Sattar S, Ahmed T, Rasul CH, Saha D, Salam MA, Hossain MI. Efficacy of a High-Dose in Addition to Daily Low-Dose Vitamin A in Children Suffering from Severe Acute Malnutrition with Other Illnesses. PLoS One 2012; 7: e33112.

49 Donnen P, Sylla A, Dramaix M, Sall G, Kuakuvi N, Hennart P. Effect of daily low dose of vitamin A compared with single high dose on morbidity and mortality of hospitalized

PeerJ reviewing PDF | (2019:09:41387:1:1:NEW 14 Apr 2020) 
950

951

952

953

954

955

956

957

958

959

960

961

962

963

964

965

966

967

968

969

970

971

972

973

974

975

976

977

978

979

980

981

982

983

984

985

986

987

988

989

990

991

992

993

994

995

mainly malnourished children in senegal: a randomized controlled clinical trial. Eur J Clin Nutr 2007; 61: 1393-1399.

50 Fawzi WW, Mbise R, Spiegelman D, Fataki M, Hertzmark E, Ndossi G. Vitamin A supplements and diarrheal and respiratory tract infections among children in Dar es Salaam, Tanzania. J Pediatr 2000; 137: 660-7.

51 Dawodu A, Wagner CL. Prevention of vitamin D deficiency in mothers and infants worldwide - a paradigm shift. Paediatr Int Child Health 2012; 32: 3-13.

52 Winzenberg T, Powell S, Shaw KA, Jones G. Effects of vitamin D supplementation on bone density in healthy children: systematic review and meta-analysis. BMJ 2011; 342: c7254.

53 Tergestina M, Rebekah G, Job V, Simon A, Thomas N. A randomized double-blind controlled trial comparing two regimens of vitamin D supplementation in preterm neonates. J Perinatol 2016; 36: 763-767.

54 Hollis BW, Wagner CL, Howard CR, Ebeling M, Shary JR, Smith PG, Taylor SN, Morella K, Lawrence RA, Hulsey TC. Maternal Versus Infant Vitamin D Supplementation During Lactation: A Randomized Controlled Trial. Pediatrics 2015; 136.http://pediatrics.aappublications.org/content/136/4/625.long

55 Oberhelman SS, Meekins ME, Fischer PR, Lee BR, Singh RJ, Cha SS, Gardner BM, Pettifor JM, Croghan IT, Thacher TD. Maternal vitamin D supplementation to improve the vitamin D status of breast-fed infants: a randomized controlled trial. Mayo Clin Proc 2013; 88: 1378-87.

56 Wheeler BJ, Taylor BJ, Herbison P, Haszard JJ, Mikhail A, Jones S, Harper MJ, Houghton LA. High-Dose Monthly Maternal Cholecalciferol Supplementation during Breastfeeding Affects Maternal and Infant Vitamin D Status at 5 Months Postpartum: A Randomized Controlled Trial. J Nutr 2016; 146: 1999-2006.

57 Huynh J, Lu T, Liew D, Doery JC, Tudball R, Jona M, Bhamjee R, Rodda CP. Vitamin D in newborns. A randomised controlled trial comparing daily and single oral bolus vitamin D in infants. $J$ Paediatr Child Health 2017; 53: 163-169.

58 Chandy DD, Kare J, Singh SN, Agarwal A, Das V, Singh U, Ramesh V, Bhatia V. Effect of vitamin D supplementation, directly or via breast milk for term infants, on serum 25 hydroxyvitamin D and related biochemistry, and propensity to infection: a randomised placebo-controlled trial. Br J Nutr 2016; 116: 52-58.

59 Saleem J, Zakar R, Zakar MZ, Belay M, Rowe M, Timms PM, Scragg R, Martineau AR. High-dose vitamin D3 in the treatment of severe acute malnutrition: a multicenter doubleblind randomized controlled trial. Am J Clin Nutr 2018; 107: 725-733.

60 Yakoob MY, Salam RA, Khan FR, Bhutta ZA. Vitamin D supplementation for preventing infections in children under five years of age. In: Bhutta ZA (ed). Cochrane Database of Systematic Reviews. John Wiley \& Sons, Ltd: Chichester, UK, 2016 doi:10.1002/14651858.CD008824.pub2.

61 Rooze S, Mathieu F, Claus W, Yangzom T, Yangzom D, Goyens P, de Maertelaer V. Effect of calcium and vitamin D on growth, rickets and Kashin-Beck disease in 0- to 5year-old children in a rural area of central Tibet. Trop Med Int Heal 2016; 21: 768-775.

62 Das RR, Singh M, Naik SS. Vitamin D as an adjunct to antibiotics for the treatment of acute childhood pneumonia. Cochrane Database Syst Rev 2018; 7: CD011597.

63 Kumar GT, Sachdev HS, Chellani H, Rehman AM, Singh V, Arora H, Filteau S. Effect of weekly vitamin D supplements on mortality, morbidity, and growth of low birthweight 
996

997

998

999

1000

1001

1002

1003

1004

1005

1006

1007

1008

1009

1010

1011

1012

1013

1014

1015

1016

1017

1018

1019

1020

1021

1022

1023

1024

1025

1026

1027

1028

1029

1030

1031

1032

1033

1034

1035

1036

1037

1038

1039

1040

104178

term infants in India up to age 6 months: randomised controlled trial. $B M J 2011 ; \mathbf{3 4 2}$ : d2975.

64 Mathur NB, Saini A, Mishra TK. Assessment of Adequacy of Supplementation of Vitamin D in Very Low Birth Weight Preterm Neonates: A Randomized Controlled Trial. J Trop Pediatr 2016; 28: fmv110.

65 Trilok-Kumar G, Kaur M, Rehman AM, Arora H, Rajput MM, Chugh R, Kurpad A, Sachdev HS, Filteau S. Effects of vitamin D supplementation in infancy on growth, bone parameters, body composition and gross motor development at age 3-6 years: follow-up of a randomized controlled trial. Int J Epidemiol 2015; 44: 894-905.

66 Fort P, Salas AA, Nicola T, Craig CM, Carlo WA, Ambalavanan N. A Comparison of 3 Vitamin D Dosing Regimens in Extremely Preterm Infants: A Randomized Controlled Trial. J Pediatr 2016; 174: 132-138.e1.

67 Czech-Kowalska J, Latka-Grot J, Bulsiewicz D, Jaworski M, Pludowski P, Wygledowska G, Chazan B, Pawlus B, Zochowska A, Borszewska-Kornacka MK, Karczmarewicz E, Czekuc-Kryskiewicz E, Dobrzanska A. Impact of Vitamin D Supplementation during Lactation on Vitamin D Status and Body Composition of Mother-Infant Pairs: A MAVID Randomized Controlled Trial. PLoS One 2014; 9: e107708.

68 Kerac M, Frison S, Connell N, Page B, McGrath M. Informing the management of acute malnutrition in infants aged under 6 months (MAMI): risk factor analysis using nationally-representative demographic \&amp; health survey secondary data. PeerJ 2019; 6: e5848.

69 Beard JL. Iron biology in immune function, muscle metabolism and neuronal functioning. J Nutr 2001; 131: 568S-579S; discussion 580S.

70 Neuberger A, Okebe J, Yahav D, Paul M. Oral iron supplements for children in malariaendemic areas. In: Paul M (ed). Cochrane Database of Systematic Reviews. John Wiley \& Sons, Ltd: Chichester, UK, 2016 doi:10.1002/14651858.CD006589.pub4.

71 Brabin L, Brabin BJ, Gies S. Influence of iron status on risk of maternal or neonatal infection and on neonatal mortality with an emphasis on developing countries. Nutr Rev 2013; 71: 528-540.

72 Paganini D, Uyoga M, Zimmermann M. Iron Fortification of Foods for Infants and Children in Low-Income Countries: Effects on the Gut Microbiome, Gut Inflammation, and Diarrhea. Nutrients 2016; 8: 494.

73 Mclean E, Cogswell M, Egli I, Wojdyla D, De Benoist B. Worldwide prevalence of anaemia, WHO Vitamin and Mineral Nutrition Information System, 1993-2005. Public Health Nutr 2008. doi:10.1017/S1368980008002401.

74 Thakur N, Chandra J, Pemde H, Singh V. Anemia in severe acute malnutrition. Nutrition 2014; 30: 440-442.

75 Arya AK, Kumar P, Midha T, Singh M. Hematological profile of children with severe acute malnutrition: a tertiary care centre experience. Int J Contemp Pediatr 2017; 0. doi:10.18203/2349-3291.ijcp20173072.

76 Ziegler EE, Nelson SE, Jeter JM. Iron supplementation of breastfed infants. Nutr Rev 2011; 69. doi:10.1111/j.1753-4887.2011.00438.x.

77 Mills RJ, Davies MW. Enteral iron supplementation in preterm and low birth weight infants. In: Mills RJ (ed). Cochrane Database of Systematic Reviews. John Wiley \& Sons, Ltd: Chichester, UK, 2012 doi:10.1002/14651858.CD005095.pub2.

78 De-Regil LM, Suchdev PS, Vist GE, Walleser S, Peña-Rosas JP. Home fortification of

PeerJ reviewing PDF | (2019:09:41387:1:1:NEW 14 Apr 2020) 
1042

1043

1044

1045

1046

1047

1048

1049

1050

1051

1052

1053

1054

1055

1056

1057

1058

1059

1060

1061

1062

1063

1064

1065

1066

1067

1068

1069

1070

1071

1072

1073

1074

1075

1076

1077

1078

1079

1080

1081

1082

1083

1084

1085

1086

1087

foods with multiple micronutrient powders for health and nutrition in children under two years of age. In: De-Regil LM (ed). Cochrane Database of Systematic Reviews. John Wiley \& Sons, Ltd: Chichester, UK, 2011 doi:10.1002/14651858.CD008959.pub2.

79 Thompson J, Biggs B-A, Pasricha S-R. Effects of Daily Iron Supplementation in 2- to 5Year-Old Children: Systematic Review and Meta-analysis. Pediatrics 2013; 131.

80 Low M, Farrell A, Biggs B-A, Pasricha S-R. Effects of daily iron supplementation in primary-school-aged children: systematic review and meta-analysis of randomized controlled trials. CMAJ 2013; 185: E791-802.

81 Dewey KG, Domellö M, Cohen RJ, Rivera LL, Hernell O, Lö B. Community and International Nutrition Iron Supplementation Affects Growth and Morbidity of Breast-Fed Infants: Results of a Randomized Trial in Sweden and Honduras 1. J Nutr 2002; 132: 3249-3255.

82 Szajewska H, Ruszczynski M, Chmielewska A. Effects of iron supplementation in nonanemic pregnant women, infants, and young children on the mental performance and psychomotor development of children: a systematic review of randomized controlled trials. Am J Clin Nutr 2010; 91: 1684-1690.

83 Olney DK, Pollitt E, Kariger PK, Khalfan SS, Ali NS, Tielsch JM, Sazawal S, Black R, Allen LH, Stoltzfus RJ. Combined iron and folic acid supplementation with or without zinc reduces time to walking unassisted among Zanzibari infants 5- to 11-mo old. J Nutr 2006; 136: 2427-34.

84 Katz J, Khatry SK, LeClerq SC, Mullany LC, Yanik EL, Stoltzfus RJ, Siegel EH, Tielsch JM. Daily Supplementation with Iron Plus Folic Acid, Zinc, and Their Combination Is Not Associated with Younger Age at First Walking Unassisted in Malnourished Preschool Children from a Deficient Population in Rural Nepal. J Nutr 2010; 140: 1317-1321.

85 Sachdev H, Gera T, Nestel P. Effect of iron supplementation on physical growth in children: systematic review of randomised controlled trials. 2005. doi:10.1017/PHN2005918.

86 Berglund SK, Westrup B, Domellöf M. Iron Supplementation Until 6 Months Protects Marginally Low-Birth-Weight Infants From Iron Deficiency During Their First Year of Life. J Pediatr Gastroenterol Nutr 2015; 60: 390-395.

87 Berglund SK, Chmielewska A, Starnberg J, Westrup B, Hägglöf B, Norman M, Domellöf M. Effects of iron supplementation of low-birth-weight infants on cognition and behavior at 7 years: a randomized controlled trial. Pediatr Res 2018; 83: 111-118.

88 Gera T, MacPhail C, Das JK, Bhutta ZA, Ahmed I, Zaidi A, Bhutta Z, Quick R, Quick R, Juliao P. Effect of iron supplementation on incidence of infectious illness in children: systematic review. BMJ 2002; 325: 1142-1142.

89 World Health Organization. Guideline: Daily iron supplementation in infants and children. Geneva; 2016.

90 Lönnerdal B. Excess iron intake as a factor in growth, infections, and development of infants and young children. Am J Clin Nutr 2017; 106: 1681S-1687S.

91 Nissensohn M, Sánchez-Villegas A, Fuentes Lugo D, Henríquez Sánchez P, Doreste Alonso J, Peña Quintana L, Ruano C, Lowe NL, Hall Moran V, Skinner AL, WarthonMedina M, Serra-Majem L. Effect of Zinc Intake on Growth in Infants: A Meta-analysis. Crit Rev Food Sci Nutr 2016; 56: 350-363.

92 Wessells KR, Brown KH. Estimating the Global Prevalence of Zinc Deficiency: Results Based on Zinc Availability in National Food Supplies and the Prevalence of Stunting.

Peer] reviewing PDF | (2019:09:41387:1:1:NEW 14 Apr 2020) 
1088

1089

1090

1091

1092

1093

1094

1095

1096

1097

1098

1099

1100

1101

1102

1103

1104

1105

1106

1107

1108

1109

1110

1111

1112

1113

1114

1115

1116

1117

1118

1119

1120

1121

1122

1123

1124

1125

1126

1127

1128

1129

1130

1131

1132

1133

PLoS One 2012; 7: e50568.

93 Castillo-Duran C, Heresi G, Fisberg M, Uauy R. Controlled trial of zinc supplementation during recovery from malnutrition: effects on growth and immune function. Am J Clin Nutr 1987; 45: 602-8.

94 Roy SK, Tomkins AM, Haider R, Behren RH, Akramuzzaman SM, Mahalanabis D, Fuchs GJ. Impact of zinc supplementation on subsequent growth and morbidity in Bangladeshi children with acute diarrhoea. Eur J Clin Nutr 1999; 53: 529-34.

95 Makonnen B, Venter A, Joubert G. A randomized controlled study of the impact of dietary zinc supplementation in the management of children with protein-energy malnutrition in Lesotho. I: Mortality and morbidity. $J$ Trop Pediatr 2003; 49: 340-52.

96 Umeta M, West CE, Haidar J, Deurenberg P, Hautvast JG. Zinc supplementation and stunted infants in Ethiopia: a randomised controlled trial. Lancet 2000; 355: 2021-2026.

97 Doherty CP, Sarkar MA, Shakur MS, Ling SC, Elton RA, Cutting WA. Zinc and rehabilitation from severe protein-energy malnutrition: higher-dose regimens are associated with increased mortality. Am J Clin Nutr 1998; 68: 742-8.

98 Lazzerini M, Wanzira H. Oral zinc for treating diarrhoea in children. In: Lazzerini M (ed). Cochrane Database of Systematic Reviews. John Wiley \& Sons, Ltd: Chichester, UK, 2016 doi:10.1002/14651858.CD005436.pub5.

99 Lassi ZS, Moin A, Bhutta ZA. Zinc supplementation for the prevention of pneumonia in children aged 2 months to 59 months. In: Bhutta ZA (ed). Cochrane Database of Systematic Reviews. John Wiley \& Sons, Ltd: Chichester, UK, 2016 doi:10.1002/14651858.CD005978.pub3.

100 Banupriya N, Bhat BV, Benet BD, Catherine C, Sridhar MG, Parija SC. Short Term Oral Zinc Supplementation among Babies with Neonatal Sepsis for Reducing Mortality and Improving Outcome - A Double-Blind Randomized Controlled Trial. Indian J Pediatr 2018; 85: 5-9.

101 Brown KH, Peerson JM, Baker SK, Hess SY, Eisele TP, Ferguson J, Jhass A, Rudan I, Campbell H, Black RE, Bhutta ZA. Preventive Zinc Supplementation among Infants, Preschoolers, and Older Prepubertal Children. Food Nutr Bull 2009; 30: S12-S40.

102 Mayo-Wilson E, Junior JA, Imdad A, Dean S, Chan XHS, Chan ES, Jaswal A, Bhutta ZA. Zinc supplementation for preventing mortality, morbidity, and growth failure in children aged 6 months to 12 years of age. In: Bhutta ZA (ed). Cochrane Database of Systematic Reviews. John Wiley \& Sons, Ltd: Chichester, UK, 2014 doi:10.1002/14651858.CD009384.pub2.

103 Wang L, Song Y. Efficacy of zinc given as an adjunct to the treatment of severe pneumonia: A meta-analysis of randomized, double-blind and placebo-controlled trials. Clin Respir J 2017. doi:10.1111/crj.12646.

104 Imdad A, Bhutta ZA, Stephen C, Naidoo K, McKerrow N, Black R, Moss W, Hainsworth L, Umbreit J, Conrad M. Effect of preventive zinc supplementation on linear growth in children under 5 years of age in developing countries: a meta-analysis of studies for input to the lives saved tool. BMC Public Health 2011; 11: S22.

105 Ramakrishnan U, Nguyen P, Martorell R. Effects of micronutrients on growth of children under 5 y of age: meta-analyses of single and multiple nutrient interventions. Am J Clin Nutr 2008; 89: 191-203.

106 Liu E, Pimpin L, Shulkin M, Kranz S, Duggan C, Mozaffarian D, Fawzi W. Effect of Zinc Supplementation on Growth Outcomes in Children under 5 Years of Age. Nutrients 2018; 
1134

1135

1136

1137

1138

1139

1140

1141

1142

1143

1144

1145

1146

1147

1148

1149

1150

1151

1152

1153

1154

1155

1156

1157

1158

1159

1160

1161

1162

1163

1164

1165

1166

1167

1168

1169

1170

1171

1172

1173

1174

1175

1176

1177

1178

1179
10: 377 .

107 Gogia S, Sachdev HS. Zinc supplementation for mental and motor development in children. In: Gogia S (ed). Cochrane Database of Systematic Reviews. John Wiley \& Sons, Ltd: Chichester, UK, 2012 doi:10.1002/14651858.CD007991.pub2.

108 Gulani A, Bhatnagar S, Sachdev H. Neonatal Zinc Supplementation for Prevention of Mortality and Morbidity in Breastfed Low Birth Weight Infants: Systematic Review of Randomized Controlled Trials. INDIAN Pediatr 2011; 111.

109 El, Sayed HM El, Elghorab AMS. Effect of zinc supplementation on growth of preterm infants. Menoufia Med J 2016; 29: 1112.

110 El-Farghali O, El-Wahed MA, Hassan NE, Imam S, Alian K. Early Zinc Supplementation and Enhanced Growth of the Low-Birth Weight Neonate. Open access Maced J Med Sci 2015; 3: 63-8.

111 Terrin G, Berni Canani R, Passariello A, Messina F, Conti MG, Caoci S, Smaldore A, Bertino E, De Curtis M. Zinc supplementation reduces morbidity and mortality in verylow-birth-weight preterm neonates: a hospital-based randomized, placebo-controlled trial in an industrialized country. Am J Clin Nutr 2013; 98: 1468-1474.

112 Friel JK, Andrews WL, Matthew JD, Long DR, Cornel AM, Cox M, McKim E, Zerbe GO. Zinc supplementation in very-low-birth-weight infants. J Pediatr Gastroenterol Nutr 1993; 17: 97-104.

113 Díaz-Gómez NM, Doménech E, Barroso F, Castells S, Cortabarria C, Jiménez A. The Effect of Zinc Supplementation on Linear Growth, Body Composition, and Growth Factors in Preterm Infants. Pediatrics 2003; 111).

114 Sazawal S, Black RE, Menon VP, Dinghra P, Caulfield LE, Dhingra U, Bagati A. Zinc Supplementation in Infants Born Small for Gestational Age Reduces Mortality: A Prospective, Randomized, Controlled Trial. Pediatrics 2001; 108.

115 Mathur N, Agarwal DK. Zinc supplementation in preterm neonates and neurological development: A randomized controlled trial. Indian Pediatr 2015; 52: 951-955.

116 World Health Organization. The Treatment of Diarrhoea: A manual for physicians and other senior health workers. 2005

117 Institute of Medicine (U.S.). Panel on Micronutrients. DRI : dietary reference intakes for vitamin A, vitamin $K$, arsenic, boron, chromium, copper, iodine, iron, manganese, molybdenum, nickel, silicon, vanadium, and zinc: a report of the Panel on Micronutrients ... and the Standing Committee on the Scientific Evaluation of Dietary Reference Intakes, Food and Nutrition Board, Institute of Medicine. National Academy Press, 2001.

118 Dumrongwongsiri O, Suthutvoravut U, Chatvutinun S, Phoonlabdacha P, Sangcakul A, Siripinyanond A, Thiengmanee U, Chongviriyaphan N. Maternal zinc status is associated with breast milk zinc concentration and zinc status in breastfed infants aged 4-6 months. Asia Pac J Clin Nutr 2015; 24: 273-80.

119 Yalcin SS, Yalcin S, Gucus AI. Zinc and Copper Concentrations in Breast Milk During the First Nine Months of Lactation: A Longitudinal Study. Pediatrics 2015; 135: S13S14.

120 Bailey RL, West KP, Black RE. The epidemiology of global micronutrient deficiencies. Ann Nutr Metab 2015; 66 Suppl 2: 22-33.

121 Kupka R. The role of folate in malaria - implications for home fortification programmes among children aged 6-59 months. Matern Child Nutr 2015; 11: 1-15.

122 Sazawal S, Black RE, Ramsan M, Chwaya HM, Stoltzfus RJ, Dutta A, Dhingra U, Kabole 
1180

1181

1182

1183

1184

1185

1186

1187

1188

1189

1190

1191

1192

1193

1194

1195

1196

1197

1198

1199

1200

1201

1202

1203

1204

1205

1206

1207

1208

1209

1210

1211

1212

1213

1214

1215

1216

1217

1218

1219

1220

1221

1222

1223

1224

1225

I, Deb S, Othman MK, Kabole FM. Effects of routine prophylactic supplementation with iron and folic acid on admission to hospital and mortality in preschool children in a high malaria transmission setting: community-based, randomised, placebo-controlled trial. Lancet 2006; 367: 133-43.

123 Tielsch JM, Khatry SK, Stoltzfus RJ, Katz J, LeClerq SC, Adhikari R, Mullany LC, Shresta S, Black RE. Effect of routine prophylactic supplementation with iron and folic acid on preschool child mortality in southern Nepal: community-based, clusterrandomised, placebo-controlled trial. Lancet 2006; 367: 144-152.

124 Taneja S, Strand TA, Kumar T, Mahesh M, Mohan S, Manger MS, Refsum H, Yajnik CS, Bhandari N. Folic acid and vitamin B-12 supplementation and common infections in 6-30mo-old children in India: a randomized placebo-controlled trial. Am J Clin Nutr 2013; 98: 731-737.

125 Medeiros D, Hadler M, Sugai A, Torres V. The effect of folic acid supplementation with ferrous sulfate on the linear and ponderal growth of children aged 6-24 months: a randomized controlled trial. Eur J Clin Nutr 2015; 69220: 198-204.

126 Foged N, Lillquist K, Rolschau J, Blaabjerg O. Effect of folic acid supplementation on small-for-gestational-age infants born at term. Eur J Pediatr 1989; 149: 65-7.

127 Kendall AC, Jones EE, Wilson CI, Shinton NK, Elwood PC. Folic acid in low birthweight infants. Arch Dis Child 1974; 49: 736-8.

128 Ek J, Behncke L, Halvorsen KS, Magnus E. Plasma and red cell folate values and folate requirements in formula-fed premature infants. Eur J Pediatr 1984; 142: 78-82.

129 Carter JY, Loolpapit MP, Lema OE, Tome JL, Nagelkerke NJD, Watkins WM. Reduction of the efficacy of antifolate antimalarial therapy by folic acid supplementation. Am J Trop Med Hyg 2005; 73: 166-70.

130 van Hensbroek MB, Morris-Jones S, Meisner S, Jaffar S, Bayo L, Dackour R, Phillips C, Greenwood BM. Iron, but not folic acid, combined with effective antimalarial therapy promotes haematological recovery in African children after acute falciparum malaria. Trans R Soc Trop Med Hyg 1995; 89: 672-676.

131 Mulenga M, Malunga P, Bennett S, Thuma P, Shulman C, Fielding K, Greenwood B. Folic acid treatment of Zambian children with moderate to severe malaria anemia. $\mathrm{Am} \mathrm{J}$ Trop Med Hyg 2006; 74: 986-990.

132 Abe SK, Balogun OO, Ota E, Takahashi K, Mori R. Supplementation with multiple micronutrients for breastfeeding women for improving outcomes for the mother and baby. In: Mori R (ed). Cochrane Database of Systematic Reviews. John Wiley \& Sons, Ltd: Chichester, UK, 2016 doi:10.1002/14651858.CD010647.pub2.

133 Delgado-Noguera MF, Calvache JA, Bonfill Cosp X, Kotanidou EP, Galli-Tsinopoulou A. Supplementation with long chain polyunsaturated fatty acids (LCPUFA) to breastfeeding mothers for improving child growth and development. In: Delgado-Noguera MF (ed). Cochrane Database of Systematic Reviews. John Wiley \& Sons, Ltd: Chichester, UK, 2015 doi:10.1002/14651858.CD007901.pub3.

134 Quin C, Erland BM, Loeppky JL, Gibson DL. Omega-3 polyunsaturated fatty acid supplementation during the pre and post-natal period: A meta-analysis and systematic review of randomized and semi-randomized controlled trials. J Nutr Intermed Metab 2016; 5: 34-54.

135 Li G, Chen H, Zhang W, Tong Q, Yan Y. Effects of maternal omega-3 fatty acids supplementation during pregnancy/lactation on body composition of the offspring: A 
1226

1227

1228

1229

1230

1231

1232

1233

1234

1235

1236

1237

1238

1239

1240

1241

1242

1243

1244

1245

1246

1247

1248

1249

1250

1251

1252

1253

1254

1255

1256

1257

1258

1259

1260

1261

1262

1263

1264

1265

1266

1267

1268

1269 systematic review and meta-analysis. Clin Nutr 2018; 37: 1462-1473.

136 Huynh DTT, Tran NT, Nguyen LT, Berde Y, Low YL. Impact of maternal nutritional supplementation in conjunction with a breastfeeding support program on breastfeeding performance, birth, and growth outcomes in a Vietnamese population. J Matern Neonatal Med 2017; : 1-9.

137 Talbert A, Thuo N, Karisa J, Chesaro C, Ohuma E, Ignas J, Berkley JA, Toromo C, Atkinson S, Maitland K. Diarrhoea complicating severe acute malnutrition in kenyan children: A prospective descriptive study of risk factors and outcome. PLoS One 2012; 7. doi:10.1371/journal.pone.0038321.

138 Irena AH, Mwambazi M, Mulenga V. Diarrhea is a major killer of children with severe acute malnutrition admitted to inpatient set-up in Lusaka, Zambia. Nutr J 2011; 10. doi:10.1186/1475-2891-10-110.

139 World Health Organization. Pocket book of hospital care for children: guidelines for the management of common childhood illnesses. 2013.

140 Houston KA, Gibb JG, Maitland K, Denmark AB, Johanne M, Rytter H. Oral rehydration of malnourished children with diarrhoea and dehydration: A systematic review. 2017; : 66 .

141 Murtaza A, Zulfiqar I, Khan SR, Lindblad BS, Aperia A. Regulation of serum sodium in dehydrated and orally rehydrated infants. Influence of age and of purging rates. Acta Paediatr Scand 1987; 76: 424-30.

142 Marin L, Sanér G, Sökücü S, Günoz H, Neyzi O, Zetterström R. Oral rehydration therapy in neonates and young infants with infectious diarrhoea. Acta Paediatr Scand 1987; 76: 431-7.

143 Elliott EJ, Cunha-Ferreira R, Walker-Smith JA, Farthing MJ. Sodium content of oral rehydration solutions: a reappraisal. Gut 1989; 30: 1610-21.

144 Gregorio G V., Dans LF, Silvestre MA. Early versus delayed refeeding for children with acute diarrhoea. Evidence-Based Child Heal. 2012; 7: 721-757.

145 Shane AL, Mody RK, Crump JA, Tarr PI, Steiner TS, Kotloff K, Langley JM, Wanke C, Warren CA, Cheng AC, Cantey J, Pickering LK. 2017 Infectious Diseases Society of America Clinical Practice Guidelines for the Diagnosis and Management of Infectious Diarrhea. Clin. Infect. Dis. 2017; 65: 1963-1973.

146 Guarino A, Lo Vecchio A, Dias JA, Berkley JA, Boey C, Bruzzese D, Cohen MB, Cruchet S, Liguoro I, Salazar-Lindo E, Sandhu B, Sherman PM, Shimizu T. Universal Recommendations for the Management of Acute Diarrhea in Nonmalnourished Children. J Pediatr Gastroenterol Nutr 2018; 67: 586-593.

147 Alam NH, Hamadani JD, Dewan N, Fuchs GJ. Efficacy and safety of a modified oral rehydration solution (ReSoMaL) in the treatment of severely malnourished children with watery diarrhea. J Pediatr 2003; 143: 614-619.

148 Kumar R, Kumar P, Aneja S, Kumar V, Rehan HS. Safety and efficacy of low-osmolarity ORS vs. modified rehydration solution for malnourished children for treatment of children with severe acute malnutrition and diarrhea: A randomized controlled trial. $J$ Trop Pediatr 2015; 61: 435-441. 


\section{Figure 1}

Abbreviations and definitions

* Standardised definitions of malnutrition have not been specified by the authors for this review and there is variation in the metrics included studies have used to define these. 
Child - Those 12 months or older (upper age limit not defined)

EBF - Exclusive breastfeeding

Infant(s) - Children under 12 months of age. Where infants under 6 months of age are referenced, this is specified as U6M.

Low birthweight (LBW) - Birth weight less than 2.5kg. LBW can be a consequence of preterm birth, or due to small for gestational age (SGA), or both ${ }^{13}$

IPTp - intermittent preventive treatment in pregnancy (malaria)

IV - Intravenous

MA - Meta-analysis

MAM - Moderate acute malnutrition*

MUAC - mid-upper-arm circumference

ORS - oral rehydration salts/solution

Pre-term - Birth before 37 completed weeks of gestation ${ }^{12}$

ReSoMal - oral rehydration solution for severely malnourished children

RCT - Randomised-controlled trial

RUTF - Ready-to-use therapeutic food

SAM - Severe acute malnutrition*

Small for gestational age (SGA) - Weight for gestation $<10^{\text {th }}$ percentile $^{13}$

SMC - Seasonal malarial chemoprophylaxis

SR - Systematic review

U6M - Under six months of age

WAZ - Weight-for-age z-score

WHZ/WLZ - weight-for-height/-length z-score

Very Low Birthweight (VLBW) - birthweight less than $1.5 \mathrm{~kg}^{13}$ 
Figure 2

Distribution of included articles presented by population studied and study design

$\mathrm{SR}=$ Systematic Review, $\mathrm{MA}=$ Meta-analysis, $\mathrm{RCT}=$ randomised controlled trial

'Malnourished' describes any definition of severe malnutrition. 


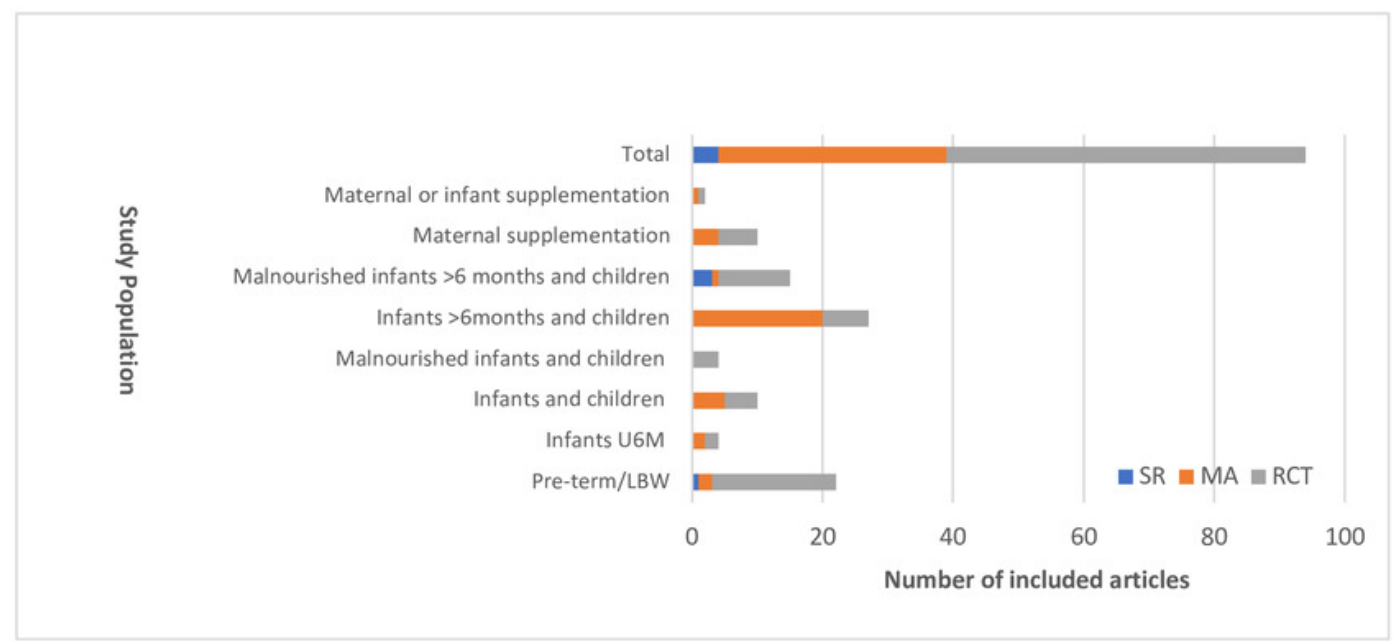




\section{Table 1 (on next page)}

Summary of current recommendations for antimicrobial and micronutrient supplementation amongst LBW/VLBW infants and children with SAM (WHO)7,13 7,13

VLBW: very low birth weight; SAM: severe acute malnutrition

* Recommendation specifically for VLBW infants only.

**Range based upon composition of commercial F-75/F-100 at 130ml/kg/day volumes

+ If not on therapeutic milk (e.g. F75/F100) or ready-to-use therapeutic food (RUTF) 
1 Table 1: Summary of current recommendations for antimicrobial and micronutrient

2 supplementation amongst LBW/VLBW infants and children with SAM (WHO) 7,13

3

\begin{tabular}{|c|c|c|}
\hline Intervention & VLBW/LBW infants & Children (aged 6-59 months) with SAM \\
\hline Antibiotics & - & Yes \\
\hline Deworming & - & $\begin{array}{l}\text { Antihelminthics during rehabilitation phase if high } \\
\text { prevalence region or evidence of infestation }\end{array}$ \\
\hline Vitamin A & Not recommended & $\begin{array}{c}5,000 \mathrm{IU} \text { daily } \\
\text { High dose regimen }(50,000-200,000 \mathrm{IU}) \text { if eye signs } \\
\text { or recent measles }\end{array}$ \\
\hline Vitamin D & $\begin{array}{l}\text { 400-1000IU/day until } 6 \text { months of } \\
\text { age* }\end{array}$ & $\begin{array}{c}\text { No recommendation } \\
\text { Therapeutic feeds provide } 135-300 \mathrm{IU} / \mathrm{kg} / \text { day } * *\end{array}$ \\
\hline Folic Acid & - & $5 \mathrm{mg}$ day $1,1 \mathrm{mg}$ daily thereafter ${ }^{+}$ \\
\hline Iron & $\begin{array}{c}2-4 \mathrm{mg} / \mathrm{kg} / \text { day from } 2 \text { weeks to } 6 \\
\text { months of age* }\end{array}$ & $\begin{array}{c}3 \mathrm{mg} / \mathrm{kg} \text { after } 2 \text { days on F-100 formula. (Not if } \\
\text { receiving RUTF) }\end{array}$ \\
\hline Zinc & Not recommended & $2 \mathrm{mg} / \mathrm{kg} / \mathrm{day}^{+}$ \\
\hline Copper & - & $0.3 \mathrm{mg} / \mathrm{kg} / \mathrm{day}^{+}$ \\
\hline Calcium & $120-140 \mathrm{mg} / \mathrm{kg} /$ day if breastmilk fed* & $\begin{array}{c}\text { No recommendation } \\
\text { Therapeutic feeds provide: } 100 \mathrm{mg} / \mathrm{kg} / \text { day** }\end{array}$ \\
\hline Phosphorous & 60-90mg/kg/day day if breastmilk fed & $\begin{array}{c}\text { No recommendation } \\
\text { Therapeutic feeds provide: } 100 \mathrm{mg} / \mathrm{kg} / \text { day } * *\end{array}$ \\
\hline
\end{tabular}

$4 V L B W$ : very low birth weight; SAM: severe acute malnutrition

$5 *$ Recommendation specifically for VLBW infants only.

$6 \quad * *$ Range based upon composition of commercial F-75/F-100 at $130 \mathrm{ml} / \mathrm{kg} /$ day volumes

$7+{ }^{+}$If not on therapeutic milk (e.g. F75/F100) or ready-to-use therapeutic food (RUTF) 


\section{Table 2 (on next page)}

Distribution of studies reporting on adverse effects by antimicrobial or micronutrient intervention 
1 Table 2: Distribution of studies reporting on adverse effects by antimicrobial or micronutrient

2 intervention

3

\begin{tabular}{cccc}
\hline Intervention & $\begin{array}{c}\text { Adverse effects } \\
\text { documented }\end{array}$ & $\begin{array}{c}\text { Adverse events not } \\
\text { documented }\end{array}$ & Total \\
\hline Antibiotics & 8 & 0 & 8 \\
Deworming & 4 & 4 & 8 \\
Vitamin A & 6 & 1 & 7 \\
Vitamin D & 13 & 3 & 16 \\
Iron & 8 & 5 & 13 \\
Zinc & 10 & 14 & 24 \\
Folic Acid & 6 & 4 & 10 \\
Maternal supplementation & 2 & 3 & 5 \\
ReSoMal & 3 & 0 & 94 \\
\hline Total & 60 & 34 & \\
\hline
\end{tabular}

4 


\section{Table 3(on next page)}

Summary of results by antimicrobial and micronutrient intervention 


\section{Table 3: Summary of results by antimicrobial and micronutrient intervention}

Antibiotics:

Current evidence, high mortality rates, higher rates of bacteraemia in the malnourished infant population and lower specificity of clinical signs for serious infections than in older age groups make divergence from current guidelines difficult to justify for infants U6M.

Urgent research is required on this topic, especially for those infants who appear clinically stable and for whom risks and costs of routine antibiotic use may outweigh potential benefits. The potential roles for macrolide antibiotics in vulnerable populations, particularly in the context of global increases in antimicrobial resistance, also require further evaluation.

\section{Deworming:}

There is no evidence to support introduction of routine deworming in infants U6M based on current evidence.

There is some evidence for deworming in breastfeeding mothers of malnourished infants U6M that requires further evaluation.

\section{Vitamin A:}

Low-dose supplementation shows the potential for significant benefit in terms of mortality and diarrhoea incidence in deficient populations and in such settings should be given. However, outside of such situations of specific clinical need, routine use cannot be currently recommended given strong evidence of mild to moderate side-effects.

More research on which populations/individuals do and which do not need extra vitamin A would be valuable.

\section{Vitamin D:}

Supplementation is safe at doses reviewed within this report with evidence of efficacy in terms of growth in children over 6 months with 'uncomplicated SAM' and LBW infants, reduced morbidity in children and through maternal supplementation, potential roles in sustaining EBF. Given the fact that a considerable proportion of infants $\mathrm{U} 6 \mathrm{M}$ were born at $\mathrm{LBW}^{68}$, the current WHO recommendations for LBW of 6 months supplementation can reasonably be followed in nutritional programming for malnourished infants U6M where birth weight is unknown.

Further trials of vitamin D in malnourished infants U6M who are not LBW are warranted. There are also questions about the optimum dose, duration and mode of delivery.

\section{Iron:}

There is a lack of any strong evidence for benefits of iron supplementation in terms of mortality and morbidity but evidence of increased haemoglobin status and some neurodevelopmental benefits across age groups. Concerns, such as those raised in the WHO guidelines on iron supplementation in children ${ }^{85}$, exist about potential negative impacts of iron supplementation on growth, infection risk and malaria risk in malariaendemic settings where regions where malaria prevention and treatment systems are not in place and/or where children are already iron replete ${ }^{90}$. Routine use for all malnourished infants U6M cannot therefore be recommended, but there can be exceptions for specific individuals and/or populations for treatment of iron deficiency.

Further trials are investigating potential alternatives to simple iron salts and ways to target iron therapy.

\section{Zinc:}

Consistent evidence across age groups exists of zinc supplementation being associated with reduced morbidity and improved anthropometry, whilst mortality and neurodevelopmental impacts are more unclear. Zinc should not be supplemented as a high-dose, given mortality concerns, and its tolerability should be considered in the context of vomiting risk. Zinc should be supplemented as per diarrhoea guidelines for all severely malnourished infants U6M with diarrhoeal illnesses ${ }^{116}$. In cases where severely malnourished infants U6M are not affected by diarrhoea, we suggest that $2 \mathrm{mg} /$ day $\left(1\right.$ recommended daily allowance $\left.{ }^{117}\right)$ of zinc be 
supplemented with other micronutrients in regions where zinc deficiency has been documented. This is because breastmilk zinc concentrations have been shown to be insufficient in zinc deficient mothers ${ }^{118,119}$.

Research is urgently needed to establish zinc requirements for malnourished infants U6M.

\section{Folic acid:}

Limited evidence of benefit in the child population in terms of morbidity and growth and therefore this is not recommended as a routine intervention for malnourished infants U6M. Safety in a malaria endemic setting remains uncertain but is less concerning given SP is no longer routinely used for the treatment of malaria. Safety of folic acid supplementation should be considered in areas where SP is used for Seasonal Malarial Chemoprophylaxis (SMC) or Intermittent Preventive Treatment in pregnancy (IPTp).

Further studies investigating the role of folic acid in malnourished infants U6M are warranted but the evidence presented does not identify this as a priority area for research.

\section{Maternal macro- and micro-supplementation:}

We found insufficient evidence of the benefits of maternal supplementation to infants to justify routine use in current programming for malnourished infants U6M.

Potential benefits to the mother, not included in this review, should be considered and evaluated in more detail in further research to inform decisions in this area.

\section{ReSoMal/ORS:}

There are no studies of ReSoMal in infants U6M. Limited evidence from inpatient studies of older children with 'SAM' suggests that ReSoMal is of similar efficacy in terms of rehydration to standard ORS but that there are significant safety concerns in terms of risk of hyponatraemia. On the basis of current evidence, and the fact that infants in the first few months of life are at increased risk of water and salt retention due to immature hormonal and renal excretion mechanisms, there is no reason to change current recommendations for use of ReSoMal in malnourished infants U6M.

This age group may differ from older children in both risks and responses to treatment and is thus a priority area for clinical trials. 


\section{Table 4 (on next page)}

Compositions of commonly used oral rehydration solutions (ORS) ${ }^{7}$ 
1 Table 4: Compositions of commonly used oral rehydration solutions (ORS) ${ }^{7}$

\begin{tabular}{lcc}
\hline & WHO Standard ORS & ReSoMal \\
\hline Osmolarity (mOsm/l) & 245 & 300 \\
Sodium (mmol/l) & 75 & 45 \\
Potassium (mmol/l) & 20 & 40 \\
Chloride (mmol/l) & 65 & 76 \\
Glucose (mmol/l) & 75 & 125 \\
\hline
\end{tabular}

2

3 